
Internal Electricity Market: an Argument for Harmonization?

Niels Govaerts, Kenneth Bruninx, Hélène Le Cadre, Leonardo Meeus and Erik Delarue

TME WORKING PAPER - Energy and Environment Last update: August 2019

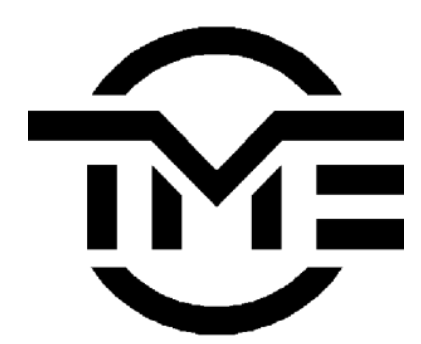

An electronic version of the paper may be downloaded from the TME website:

http://www.mech.kuleuven.be/tme/research/ 


\title{
Spillover Effects of Distribution Grid Tariffs in the Internal Electricity Market: an Argument for Harmonization?
}

\author{
Niels Govaertsa ${ }^{a, b, c}$, Kenneth Bruninx ${ }^{a, b, c}$, Hélène Le Cadre ${ }^{b, c}$, Leonardo Meeus ${ }^{\mathrm{d}, e}$, Erik \\ Delarue $^{\mathrm{a}, \mathrm{b}, *}$ \\ ${ }^{a}$ KU Leuven, Divison of Applied Mechanics and Energy Conversion, Celestijnenlaan 300 - box 2421, \\ B-3001 Leuven, Belgium \\ ${ }^{b}$ EnergyVille, Thor Park, Poort Genk 8310, B-3600 Genk, Belgium \\ ${ }^{c}$ Flemish Institute of Technological Research (VITO), Boeretang 200, B-2400 Mol, Belgium \\ ${ }^{d}$ Vlerick Business School, Vlerick Energy Centre, Bolwerklaan 21, B-1210 Brussels, Belgium \\ ${ }^{e}$ Florence School of Regulation, Robert Schuman Centre for Advanced Studies, European University \\ Institute, Via Boccaccio 121, I-50133 Florence, Italy
}

\begin{abstract}
In many countries, distribution grid tariffs are being reformed to adapt to the new realities of an electricity system with distributed energy resources. In Europe, legislative proposals have been made to harmonize these reforms across country borders. Many stakeholders have argued that distribution tariffs are a local affair, while the European institutions argued that there can be spillovers to other countries, which could justify a more harmonized approach. In this paper, we quantify these spillovers in a simplified numerical example to give insight and an order of magnitude. We look at different scenarios, and find that the spillovers can be both negative and positive. To be able to quantify these effects, we developed a longrun market equilibrium model that captures the wholesale market effects of distribution grid tariffs. The problem is formulated as a non-cooperative game involving consumers, generating companies and distribution system operators in a stylized electricity market.
\end{abstract}

Keywords: Distribution grid tariff design, Distributed energy resources, Non-cooperative game, Mixed complementarity problem, Spillovers

\footnotetext{
${ }^{*}$ Corresponding author

Email address: erik.delarue@kuleuven.be (Erik Delarue)
} 


\section{Nomenclature}

\section{Sets}

$\mathcal{A}$ Set of agents in the non-cooperative game, indexed by $a$.

$\mathcal{I} \quad$ Set of countries, indexed by $i$.

$\mathcal{J} \quad$ Set of residential consumer segments, indexed by $j$.

$\mathcal{K} \quad$ Set of conventional generator technologies, indexed by $k$.

$\mathcal{T} \quad$ Set of time steps, indexed by $t$.

\section{Parameters}

$\overline{\text { cap }_{i, j}^{\mathrm{pv}}}$ Maximum PV capacity that can be installed by consumer $C_{i, j}$, MW.

$\overline{\operatorname{cap}_{i, j}^{\mathrm{s}}}$ Maximum storage capacity that can be installed by consumer $C_{i, j}$, MWh.

CR C-rate of a storage system, MW/MWh.

CT Cost of transmission, $€ /$ MWh.

$\mathrm{C}_{i}^{\text {incr }}$ Incremental distribution network costs in country $i, € / \mathrm{MW}$.

$\mathrm{C}_{i}^{\text {sunk }}$ Total annual sunk costs of the distribution system operator in country $i, €$.

$\mathrm{D}_{t, i}^{\mathrm{nres}} \quad$ Non-residential electricity demand at time step $t, \mathrm{MWh}$.

$\mathrm{D}_{t, i, j} \quad$ Electricity demand of consumer $C_{i, j}$ at time step $t$, MWh.

EC Charging efficiency of a storage system, - .

ED Discharging efficiency of a storage system, - .

$\mathrm{IC}_{k}^{\text {conv }}$ Annualized investment cost of conventional generating technology $k, € / \mathrm{MW}$. 
$\mathrm{IC}^{\mathrm{pv}}$ Annualized investment cost of PV, $€ / \mathrm{MW}$.

IC $\quad$ Annualized investment cost of storage, $€ / M W h$.

$\mathrm{IC}^{\mathrm{w}}$ Annualized investment cost of a wind turbine, $€ / \mathrm{MW}$.

$\mathrm{LF}_{t, i}^{\mathrm{w}}$ Load factor of wind turbines at time step $t,-$.

$\mathrm{LF}_{t, i}^{\mathrm{pv}} \quad$ Load factor of PV at time step $t,-$.

$\mathrm{N}_{i, j} \quad$ Number of residential consumers belonging to segment $j$ in country $i,-$.

$\mathrm{u}_{i}^{\mathrm{fix}} \quad$ Binary parameter determining if fixed tariff structure is imposed in country $i,-$.

$\mathrm{u}_{i}^{\mathrm{nm}} \quad$ Binary parameter determining if volumetric tariff structure with net-metering is imposed in country $i,-$.

$\mathrm{u}_{i}^{\text {pd }} \quad$ Binary parameter determining if peakd demand-based tariff structure is imposed in country $i,-$.

$\mathrm{VC}_{k} \quad$ Variable cost of generating technology $k, € / \mathrm{MWh}$.

\section{Variables}

$\lambda_{t, i} \quad$ Electricity market clearing price in country $i$ at time step $t, € / \mathrm{MWh}$.

$a_{t, i} \quad$ Electricity imported by country $i$ at time step $t$, MWh.

$c_{i}^{\text {DSO }}$ Total annual costs of the distribution system operator in country $i, €$.

$\operatorname{cap}_{i, k}^{\text {conv }}$ Installed capacity of conventional generator technology $k$ in country $i$, MW.

$\operatorname{cap}_{i, j}^{\mathrm{pv}} \quad$ PV capacity installed by consumer $C_{i, j}, \mathrm{MW}$.

$c a p_{i, j}^{\mathrm{s}}$ Storage capacity installed by consumer $C_{i, j}$, MWh.

$\operatorname{cap}_{i}^{\mathrm{W}} \quad$ Installed capacity of wind turbines in country $i, \mathrm{MW}$. 
$c h_{t, i, j}$ Energy charged to storage system of consumer $C_{i, j}$ at time step $t$, MWh.

$d c_{t, i, j}$ Energy discharged from storage system of consumer $C_{i, j}$ at time step $t$, MWh.

$e_{t, i, j} \quad$ Energy content of storage system of consumer $C_{i, j}$ at time step $t$, MWh.

$f_{t} \quad$ Electricity transported over transmission line at time step $t$, MWh.

$g_{t, i, k}^{\text {conv }} \quad$ Electricity generated by conventional generator technology $k$ in country $i$ at time step $t$, MWh.

$g_{t, i, j}^{\mathrm{pv}} \quad$ Electricity generated by PV system of consumer $C_{i, j}$ at time step $t, \mathrm{MWh}$.

$g_{t, i}^{\mathrm{w}} \quad$ Electricity generated by wind turbines in country $i$ at time step $t, \mathrm{MWh}$.

$\operatorname{tar}_{i}^{\mathrm{fix}}$ Distribution tariff under the fixed tariff structure in country $i, € /$ year.

$\operatorname{tar}_{i}^{\mathrm{nm}}$ Distribution tariff under the volumetric net-metering tariff structure in country $i, € /$ MWh.

$\operatorname{tar}_{i}^{\text {pd }}$ Distribution tariff under the peakd demand-based tariff structure in country $i$, $€ / M W$.

$w_{i, j}^{\text {net }} \quad$ Net withdrawal of consumer $C_{i, j}$ over all time steps $t \in \mathcal{T}$, MWh.

$w_{i, j}^{\text {peak }}$ Peak withdrawal from or injection into the grid of consumer $C_{i, j}$ at one time step $t, \mathrm{MW}$.

$w_{t, i, j}$ Electricity withdrawn from the grid by consumer $C_{i, j}$ at time step $t$, MWh. 


\section{Introduction}

Traditional volumetric distribution grid tariffs, especially in combination with net-metering policies, have caused welfare transfers between consumers and cost recovery problems for distribution system operators (DSOs) (Eid et al., 2014). The negative effects of traditional tariff design have become apparent in recent years due to the emergence of distributed energy resources (DERs), such as residential solar photovoltaics (PV) (Picciariello et al., 2015). To address these challenges, researchers, regulators and DSOs have proposed other distribution tariff designs with different combinations and implementations of fixed, volumetric and peak demand-based charges (Abdelmotteleb et al., 2018; Hledik and Greenstein, 2016; Borenstein, 2016). Most researchers focus on designing more cost-reflective tariffs because they are more efficient in theory. Reneses and Ortega (2014) give an overview of tariff design methodologies, focusing on methods following this cost-causality principle.

At the same time, the European Commission proposes to harmonize transmission and distribution grid tariff designs on the European level in its Clean Energy Package (European Commission, 2016). These network tariffs are currently set autonomously by the national regulatory authorities (NRAs) across Europe. The European Commission argues that unharmonized distribution tariff design may distort the level playing field on the internal electricity market in Europe as production is increasingly decentralized. Indeed, distribution grid tariffs may be seen as a form of state aid for DERs. On top of this, there may be spillover effects of distribution tariffs in neighboring countries, i.e., the welfare of consumers and the business case for DERs in a country may be impacted by the distribution grid tariff design imposed in a neighboring country. Many stakeholders have, however, argued that distribution grid tariff design should remain a national prerogative (CEER, 2017; CEDEC, 2017; Eurelectric, 2017). Eurelectric (2017), for instance, agrees that transmission tariffs should be harmonized to safeguard a level playing field, but argues that this is not necessary for distribution tariffs as they are "closely linked to local specificities".

The interaction between distribution tariff structures and DER investment has been studied extensively. Many researchers focus on volumetric net-metering tariffs that incentivize 
investments in PV (Simshauser, 2016; Eid et al., 2014; Laws et al., 2017; Brown and Sappington, 2017). Simshauser (2016) finds that net-metering policies in Southeast Queensland in Australia have led to significant welfare transfers from non-solar to solar households, thus forming an "implicit subsidy" for PV. He is in favor of a tariff with a large peak demandbased component to replace the current tariffs. Schittekatte et al. (2018), however, show how peak demand-based tariffs incentivize inefficient storage investment if the DSO's costs are sunk. All aforementioned research does not regard the possible impact of these distribution tariffs on other countries. To fill this gap, this work focuses on the spillover effects of distribution grid tariffs in neighboring, interconnected countries through coupled wholesale markets. To this end, we model the interaction between residential consumers, generating companies and distribution system operators in a simplified wholesale electricity market, spanning two interconnected countries, as a non-cooperative game. For each country, we consider active consumers (who can invest in PV and storage) and passive consumers (who cannot invest). The proposed model considers the investments in large-scale generation capacity by generating companies and the DER investments by active consumers to arrive at a competitive long-run equilibrium of the electricity market. The developed model captures how DER investments in one country, induced in part by the tariff design in that country, impact the coupled wholesale market of a second country. As such, it also captures how those DER investments impact the investments and costs of residential consumers in the second country.

We consider nine scenarios through the disjoint implementation of three distribution tariff structures in two countries, i.e., a tariff consisting of a fixed charge (FIX), a tariff consisting of a peak demand charge (PD) and a tariff consisting of a volumetric charge with net-metering (NM). By comparing the costs and investments in the second country between scenarios with different tariff designs in the first country, we determine spillover effects. Assuming fully sunk network costs, we find that both positive and negative welfare spillovers, up to $3.5 \mathrm{pp}$, occur. We also find significant spillovers concerning storage investment, while PV investment spillovers do not occur under our assumptions. Afterwards, we present a first analysis of spillover effects considering variable network costs, showing that the mechanisms 
governing the spillovers and their order of magnitude remain the same, while the direction of the welfare spillovers may change.

The contribution of this work is twofold. First, to the best of our knowledge, we are the first to quantify the spillover effects of distribution grid tariffs. Second, we make a modeling contribution. We develop a long-run market equilibrium model which takes into account distribution tariffs in the decision-making problems of consumers. In the academic literature studying distribution grid tariff design, wholesale markets are typically not modeled and the energy component of the retail tariff is consequently assumed fixed (Schittekatte et al., 2018; Abdelmotteleb et al., 2018). Brown and Sappington (2017, 2018) allow the electricity tariff, including both network and energy charges, to vary, but they model a vertically-integrated utility, not a wholesale market. The application of an equilibrium modeling technique in the field of distribution grid tariff design is novel and, contrary to the aforementioned methodologies, allows analyzing the spillover effects of distribution grid tariffs.

The remainder of this paper is organised as follows. In Section 2, the market equilibrium model is developed. In Section 3, we present the results of a case study. Finally, we provide policy implications and conclusions in Section 4.

\section{Methodology}

The model presented in this section is a non-cooperative game, with coupling constraints imposed by distribution cost recovery at country-scale and endogenous determination of the wholesale market price. First, we detail the modeling approach (Section 2.1). Subsequently, we formally define the non-cooperative game in Section 2.2. The mathematical formulation is presented in Section 2.3. Finally, an algorithmic procedure for computing the solution is detailed in Section 2.4.

\subsection{Modeling approach}

On one hand, our model is inspired by traditional electricity market equilibrium models (Gabriel et al., 2013). The model output mimics the long-run equilibrium in a wholesale 
electricity market. We consider the wholesale markets of two neighboring countries, interconnected by a transmission line, in which price-taking generators, consumers and a market coupling operator participate. Equilibrium models have been extensively applied to analyze market design and/or policy measures in the power sector. For example, Höschle et al. (2018) and Ehrenmann and Smeers (2011) develop stochastic market equilibrium models to analyze capacity markets. Saguan and Meeus (2014) analyze the costs of renewable energy using a market equilibrium model representing two interconnected countries for four states of the world: with national and international transmission planning, and with and without renewable energy trade. Zhao et al. (2010) analyze the efficiency of multiple systems for allocating emission allowances with a market equilibrium model, representing an energy, capacity and emission allowance market.

On the other hand, our model is inspired by the game-theoretic model of Schittekatte et al. (2018), who formulate a game between residential consumers trying to shift distribution costs to other consumers under a sunk DSO cost recovery constraint. The cost recovery constraint is a coupling constraint, coupling the decision variables of the residential consumers and reflecting the tariff-setting process of a DSO. As a result, residential consumers play a non-cooperative game, in which they can shift distribution costs to other consumers. The distribution tariff structure is exogenously set by the NRA before the game, i.e., only the level of the tariff is considered in the non-cooperative game. If a consumer manages to reduce his distribution costs, this leads to an increase of the distribution costs of the other consumers because the DSO can adapt the tariff to ensure cost recovery. Under a peak demand-based tariff structure, for instance, an active consumer may install storage to reduce his peak demand and thus his distribution costs. The DSO, monitored by the NRA, must then increase the distribution tariff to compensate this loss of revenue. This may cause the aforementioned active consumer to adapt his strategy. He could, for instance, install more storage. Finally, in the long-run equilibrium, the tariffs will be set exactly so that all costs are recovered, taking into account the actions of active consumers.

The model output can be interpreted as a Nash equilibrium of a non-cooperative game involving generators, residential consumers and a market coupling operator, linked by market 
clearing and cost recovery constraints. The non-cooperative game is a one-shot game in which all agents make their investment and operational decisions simultaneously for a whole year, based on annualized investment cost values. ${ }^{1}$ The game is schematically presented in Figure 1.

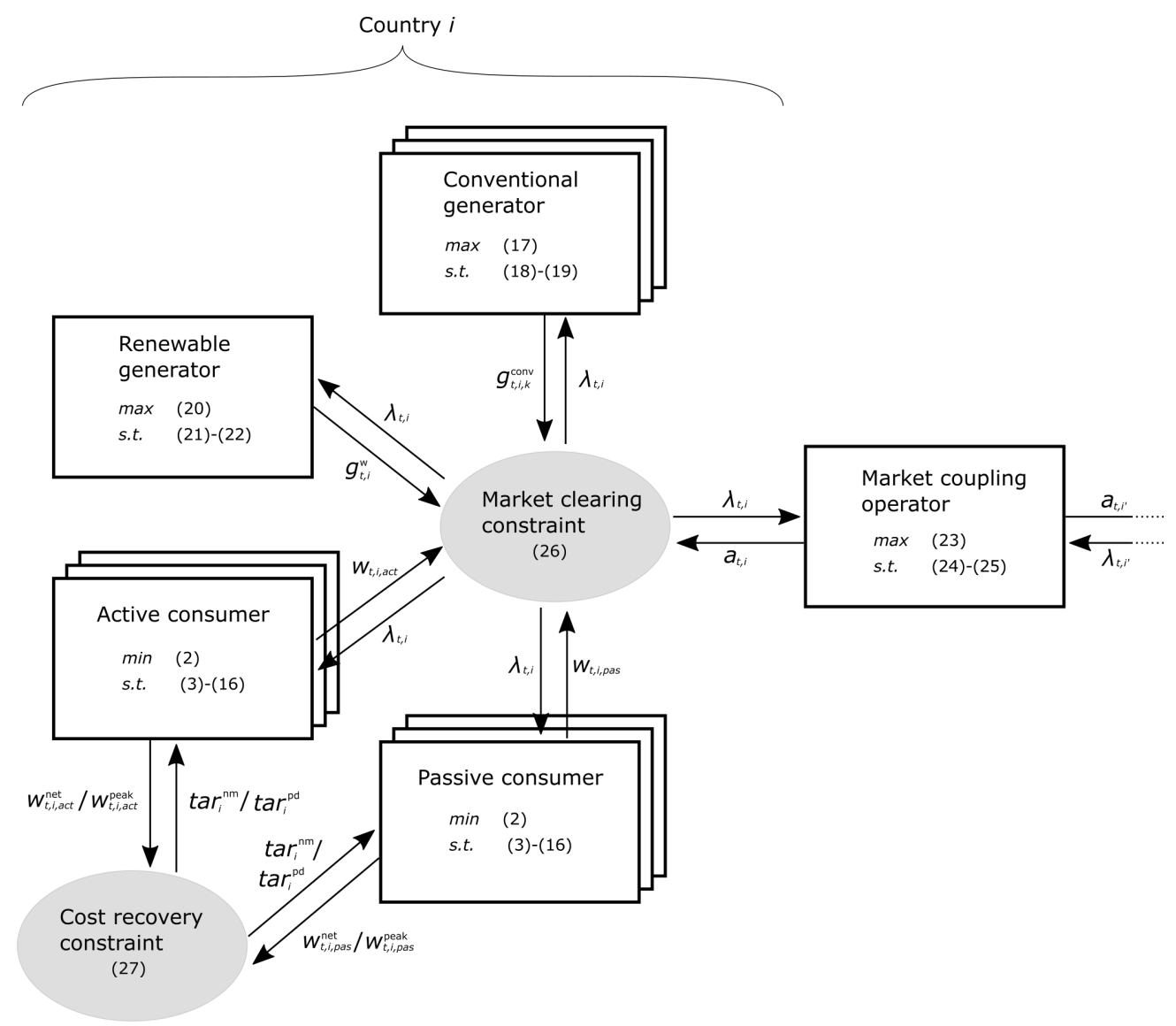

Figure 1: Schematic overview of the non-cooperative game (2)-(27). All agents are represented by rectangular boxes, while coupling constraints are represented by the grey areas. The arrows represent the coupling variables. The agents and coupling constraints in the second country $i^{\prime}$ are structured in the same way as the visualized agents and constraints belonging to country $i$. The market coupling operator is active in both countries, effectively coupling them.

The model is highly stylized due to, i.a., a number of simplifying assumptions. We assume that all consumers and generators are price-takers and that all demand is inelastic. We focus

\footnotetext{
${ }^{1}$ The agents thus implicitly assume that all future years during the lifetime of the investments will be similar to the modeled year.
} 
on residential consumers, thereby assuming that non-residential consumers cannot invest in DERs as they are not explicitly modeled. We consider an energy-only market without a price cap or other market imperfections. Short-term uncertainty and operating reserves are not considered. Both countries are connected by a transmission line with a non-binding capacity. In order to make the location of generating and storage technologies meaningful, however, we add a linear transmission cost. ${ }^{2}$ The market is cleared hourly, and we assume that residential consumers pay the hourly wholesale electricity prices for their energy use. They only consider their energy and distribution costs, along with their investments costs. Other cost components, e.g., a retail margin, taxes, etc. are disregarded. We also assume that residential consumers are unable to disconnect from the grid.

Because our focus lies on residential consumers, we only consider distribution network costs attributed to low-voltage consumers. In a first approach, we assume that they are fully sunk, which entails that the distribution network costs do not change regardless of the actions of consumers. This assumption corresponds to a short-term perspective in which (i) massive policy costs are thrust upon DSOs, and (ii) more fundamentally, grids are overdimensioned due to the traditional 'fit-and-forget' approach of distribution grid planning (Pollitt, 2018). Although this assumption does not entirely match the long-term perspective of the equilibrium model, the results and insights concerning welfare and DER investment spillovers also hold under variable network costs. To verify this, we expand the methodology in a second step to include variable network costs using a linear cost function.

\footnotetext{
${ }^{2}$ We choose this cost as such that there is no impact on the costs of consumers and that transmission is never a barrier to install generation and/or DER capacity in a particular country, if there is a clear incentive to do so. In our work, these incentives will follow from the imposed distribution tariff structures. However, the transmission cost will ensure a "logical" distribution of generation and DER capacities if the model - without the transmission costs - would be indifferent to the location of the new investment. If both countries are the same size and have imposed the same distribution tariffs, for instance, the generation and DER capacities will be equal in each country. Without the transmission cost, the location of the generation and DER capacities would be arbitrary in this instance.
} 


\subsection{Formal definition of the non-cooperative game}

In this section, we formally define the non-cooperative game. The set of agents in the game, $\mathcal{A}$, consists of representative residential consumers $\left(C_{i, j}\right)_{i \in \mathcal{I}, j \in \mathcal{J}}$ (each representative consumer representing the $\mathrm{N}_{i, j}$ identical consumers belonging to a certain consumer segment $j \in \mathcal{J}$ in a certain country $i \in \mathcal{I}$ ), conventional generators $\left(G_{i, k}\right)_{i \in \mathcal{I}, k \in \mathcal{K}}$ (aggregated per country $i \in \mathcal{I}$ and generator type $k \in \mathcal{K}$ ), one aggregated renewable (wind) generator $\left(R_{i}\right)_{i \in \mathcal{I}}$ in each country $i \in \mathcal{I}$ and a market coupling operator $M$. Each agent determines its strategy $\chi_{a} \in \mathcal{X}_{a}$ out of its set of strategies $\mathcal{X}_{a}$ by selfishly maximizing its utility $\Pi_{a}: \mathcal{X}_{a} \rightarrow \mathbb{R}$, subject to a set of constraints. The strategies of the different agents are linked via two coupling constraints: a market clearing constraint and a cost recovery constraint. The market clearing constraint reflects the actions of a market operator determining wholesale electricity prices, while the cost recovery constraint reflects the tariff-setting process of a regulated DSO. To be consistent with our general formulation, we can include the market operators and DSOs, one for each country, in the set of agents $\mathcal{A}$, each representing one constraint, i.e., the market clearing and cost recovery constraint.

Let $\mathcal{X}:=\times_{a \in \mathcal{A}} \mathcal{X}_{a}$ denote the set of all possible combinations of strategies that can be chosen by the agents in $\mathcal{A}$. The non-cooperative game between the aforementioned agents is denoted as $\Gamma:\left(\mathcal{A}, \mathcal{X},\left(\Pi_{a}\right)_{a \in \mathcal{A}}\right)$. Let $\chi_{-a}$ be the vector of strategies of all the agents in $\mathcal{A}$, except agent $a$. Then, given the strategies of the other agents in $\mathcal{A}$, each agent $a \in \mathcal{A}$ simultaneously solves:

$$
\max _{\chi_{a} \in \mathcal{X}_{a}} \Pi_{a}\left(\chi_{a}, \chi_{-a}\right)
$$

Using the classical definition from non-cooperative game theory: a Nash equilibrium is reached when no agent can unilaterally improve its utility by adapting its strategy $\chi_{a}$, given the strategies of the other agents $\chi_{-a}$.

\subsection{Mathematical formulation}

In this section, the decision-making problems of all agents are presented in detail. The dual variables associated with each constraint are given between brackets. We move to the 
specific setting of our work in which we consider two countries and two consumer segments (active and passive). This allows a straightforward formulation of the optimization problem of the market coupling operator (Section 2.3.4), while the formulations of the optimization problems of the other agents remain general.

\subsubsection{Residential consumers}

The decision variables of each representative consumer $C_{i, j}$ are his PV investment $c a p_{i, j}^{\mathrm{pv}}$, his storage investment $c a p_{i, j}^{\mathrm{s}}$, the energy produced by his PV system $g_{t, i, j}^{\mathrm{pv}}$, the energy stored in his storage system $e_{t, i, j}$, the energy charged to or discharged from his storage system $c h_{t, i, j}$ and $d c_{t, i, j}$, the energy withdrawn from or injected into the grid $w_{t, i, j}{ }^{3}$ and the DSO's billing variables $w_{i, j}^{\text {net }}$ and $w_{i, j}^{\text {peak }}$. Each consumer $C_{i, j}$ solves the optimization problem (2)-(16):

$$
\begin{aligned}
\text { Minimize } & \sum_{t \in \mathcal{T}} \lambda_{t, i} \cdot w_{t, i, j}+\mathrm{IC}^{\mathrm{pv}} \cdot c a p_{i, j}^{\mathrm{pv}}+\mathrm{IC}^{\mathrm{s}} \cdot c a p_{i, j}^{\mathrm{s}}+\mathrm{u}_{i}^{\mathrm{fix}} \cdot \operatorname{tar}_{i}^{\mathrm{fix}} \\
& +\mathrm{u}_{i}^{\mathrm{nm}} \cdot \operatorname{tar}_{i}^{\mathrm{nm}} \cdot w_{i, j}^{\mathrm{net}}+\mathrm{u}_{i}^{\mathrm{pd}} \cdot \operatorname{tar}_{i}^{\mathrm{pd}} \cdot w_{i, j}^{\mathrm{peak}}
\end{aligned}
$$

subject to

$$
\begin{aligned}
& w_{t, i, j}=\mathrm{D}_{t, i, j}+c h_{t, i, j}-d c_{t, i, j}-g_{t}^{\mathrm{pv}}, \quad \forall t \in \mathcal{T} \quad\left(\alpha_{t, i, j}\right) \\
& 0 \leqslant g_{t, i, j}^{\mathrm{pv}} \leqslant \mathrm{LF}_{t, i}^{\mathrm{pv}} \cdot c a p_{i, j}^{\mathrm{pv}}, \quad \forall t \in \mathcal{T} \quad\left(\beta_{t, i, j}^{-}, \beta_{t, i, j}^{+}\right) \\
& e_{t, i, j}=e_{t-1, i, j}+c h_{t, i, j} \cdot \mathrm{EC}-d c_{t, i, j} / \mathrm{ED}, \quad \forall t \in \mathcal{T} \backslash\{1\} \quad\left(\gamma_{t, i, j}\right) \\
& e_{1, i, j}=c a p_{i, j}^{\mathrm{s}} / 2+c h_{1, i, j} \cdot \mathrm{EC}-d c_{1, i, j} / \mathrm{ED}, \quad\left(\gamma_{1, i, j}\right) \\
& e_{T, i, j}=\operatorname{cap}_{i, j}^{\mathrm{s}} / 2, \quad\left(\delta_{i, j}\right) \\
& 0 \leqslant e_{t, i, j} \leqslant c a p_{i, j}^{\mathrm{s}}, \quad \forall t \in \mathcal{T} \quad\left(\epsilon_{t, i, j}^{-}, \epsilon_{t, i, j}^{+}\right) \\
& 0 \leqslant c h_{t, i, j} \leqslant \mathrm{CR} \cdot c a p_{i, j}^{\mathrm{s}}, \quad \forall t \in \mathcal{T} \quad\left(\zeta_{t, i, j}^{-}, \zeta_{t, i, j}^{+}\right) \\
& 0 \leqslant d c_{t, i, j} \leqslant \mathrm{CR} \cdot c a p_{i, j}^{\mathrm{s}}, \quad \forall t \in \mathcal{T} \quad\left(\eta_{t, i, j}^{-}, \eta_{t, i, j}^{+}\right) \\
& 0 \leqslant c a p_{i, j}^{\mathrm{pv}} \leqslant \overline{\operatorname{cap}_{i, j}^{\mathrm{pv}}}, \quad\left(\theta_{i, j}^{-}, \theta_{i, j}^{+}\right) \\
& 0 \leqslant \operatorname{cap}_{i, j}^{s} \leqslant \overline{\operatorname{cap}_{i, j}^{\mathrm{s}}}, \quad\left(\iota_{i, j}^{-}, \iota_{i, j}^{+}\right)
\end{aligned}
$$

\footnotetext{
${ }^{3} \mathrm{~A}$ consumer injects power into the grid if $w_{t, i, j} \leqslant 0$.
} 


$$
\begin{aligned}
& \sum_{t \in \mathcal{T}} w_{t, i, j} \leqslant w_{i, j}^{\text {net }}, \quad\left(\kappa_{i, j}^{1}\right) \\
& 0 \leqslant w_{i, j}^{\text {net }}, \quad\left(\kappa_{i, j}^{2}\right) \\
& w_{t, i, j} \leqslant w_{i, j}^{\text {peak }}, \quad \forall t \in \mathcal{T} \quad\left(\mu_{t, i, j}^{1}\right) \\
& -w_{t, i, j} \leqslant w_{i, j}^{\text {peak }}, \quad \forall t \in \mathcal{T}, \quad\left(\mu_{t, i, j}^{2}\right)
\end{aligned}
$$

Under the assumption of inelastic demand, the objective of each residential consumer (2) is to minimize his costs, equal to the sum of his energy costs (first term), investment costs (second and third term) and distribution costs (fourth, fifth and sixth term). We exogenously impose the distribution tariff structure in each country by setting one of the binary parameters $\mathrm{u}_{i}^{\mathrm{fix}}, \mathrm{u}_{i}^{\text {net }}$ and $\mathrm{u}_{i}^{\mathrm{pd}}$ equal to 1 . Under a distribution tariff with a fixed charge $\left(u_{i}^{\mathrm{fix}}=1\right)$, consumer $C_{i, j}$ pays a yearly fixed amount to the DSO, equal to $\operatorname{tar}_{i}^{\mathrm{fix}}$. Under a distribution tariff structure consisting of a volumetric charge with net-metering $\left(u_{i}^{\mathrm{nm}}=1\right)$, the distribution costs of consumer $C_{i, j}$ are proportional to the net annual offtake $w_{i, j}^{\text {net }}$ and the tariff $\operatorname{tar}_{i}^{\mathrm{nm}}$ in $€ / \mathrm{kWh}$. Finally, under a distribution tariff structure consisting of a peak-demand charge $\left(u_{i}^{\mathrm{pd}}=1\right)$, the distribution costs of consumer $C_{i, j}$ are proportional to the peak offtake or injection $w_{i, j}^{\text {peak }}$ and the tariff $\operatorname{tar}_{i}^{\mathrm{pd}}$ in $€ / \mathrm{kW}$.

Constraint (3) gives the behind-the-meter energy balance of each consumer. The hourly withdrawal from or injection into the grid of a consumer follows from his fixed demand $\mathrm{D}_{t, i, j}$, the energy (dis)charged from his storage system and the energy produced by his PV system. Equation (4) limits the PV production to the installed capacity multiplied with the load factor $\mathrm{LF}_{t, i}^{\mathrm{pv}}$ in each time step. The inequality implies that consumers are able to curtail the output of their PV system. ${ }^{4}$ Constraints (5)-(7) determine the evolution of the energy content of the storage system in time. We impose cyclical boundary conditions. Equation (8) limits the energy content to the installed storage capacity. The energy charged/discharged every hour is limited by the installed storage capacity, multiplied with the C-rate CR (Eq. (9)-(10)). Equations (11)-(12) limit the investment in PV and storage respectively. Con-

\footnotetext{
${ }^{4}$ We allow curtailment of renewables in order to ensure that investment in renewables is not limited by the necessity of avoiding excess renewable generation in order to satisfy the power balance constraint (26).
} 
straints (13) and (14) define the billing variable $w_{i, j}^{\text {net }}$, equal to the net withdrawal over all time steps $\left(\sum_{t \in \mathcal{T}} w_{t, i, j}\right)$ if the net withdrawal is positive, and zero otherwise. ${ }^{5}$ Constraints (15)-(16), define billing variable $w_{i, j}^{\text {peak }}$, equal to the maximum hourly withdrawal or injection in the period spanned by $t \in \mathcal{T}$.

\subsubsection{Conventional generators}

The decision variables of each conventional generator $G_{i, k}$ are its installed capacity $c a p_{i, k}^{\text {conv }}$ and its hourly generation $g_{t, i, k}^{\text {conv }}$. Each conventional generator solves the optimization problem (17)-(19):

$$
\begin{aligned}
& \text { Maximize } \sum_{t \in \mathcal{T}}\left(\lambda_{t, i}-\mathrm{VC}_{k}\right) \cdot g_{t, i, k}^{\text {conv }}-\mathrm{IC}_{k}^{\text {conv }} \cdot \operatorname{cap}_{i, k}^{\text {conv }} \\
& \text { subject to } \\
& 0 \leqslant g_{t, i, k}^{\text {conv }} \leqslant \operatorname{cap}_{i, k}^{\text {conv }}, \quad \forall t \in \mathcal{T} \quad\left(\nu_{t, i, k}^{-}, \nu_{t, i, k}^{+}\right) \\
& 0 \leqslant \operatorname{cap}_{i, k}^{\text {conv }}, \quad\left(\xi_{i, k}\right)
\end{aligned}
$$

The objective of each generator (17) is to maximize its profit, equal to its revenues corrected for its operational and investment costs. The revenues depend on the market clearing price $\lambda_{t, i}$. The operational costs are proportional to the variable costs of the generator $\mathrm{VC}_{k}$ while the annualized investment costs are governed by $\mathrm{IC}_{k}^{\mathrm{conv}}$. Constraint (18) limits the production to the installed generation capacity.

\subsubsection{Renewable generators}

Because each renewable generator $R_{i}$ can only invest in wind generation, its decision variables are the installed capacity of wind turbines $c a p_{i}^{\mathrm{w}}$ and the hourly generation of those wind turbines $g_{t, i}^{\mathrm{w}}$ considering the availability of the wind resource. Each renewable generator solves the optimization problem (20)-(22):

\footnotetext{
${ }^{5}$ If $u_{i}^{\text {nm }}=1, w_{i, j}^{\text {net }}$ will always be chosen as small as possible, subject to constraints (13)-(14), as that choice minimizes the objective considering the tariff $\operatorname{tar}_{i}^{\mathrm{nm}}$ is never negative.
} 


$$
\begin{aligned}
& \text { Maximize } \sum_{t \in \mathcal{T}} \lambda_{t, i} \cdot g_{t, i}^{\mathrm{w}}-\mathrm{IC}^{\mathrm{w}} \cdot c a p_{i}^{\mathrm{w}} \\
& \text { subject to } \\
& 0 \leqslant g_{t, i}^{\mathrm{w}} \leqslant \mathrm{LF}_{t, i}^{\mathrm{w}} \cdot \operatorname{cap}_{i}^{\mathrm{w}}, \quad \forall t \in \mathcal{T} \quad\left(o_{t, i}^{-}, o_{t, i}^{+}\right) \\
& 0 \leqslant \operatorname{cap}_{i}^{\mathrm{w}}, \quad\left(\pi_{i}\right)
\end{aligned}
$$

Similar to conventional generators, the objective of each renewable generator (20) is to maximize its profit, equal to its revenues, which depend on the market clearing, corrected for the investment costs, proportional to the annualized investment costs $\mathrm{IC}^{\mathrm{w}}$. We assume that wind generation has no variable costs. Constraint (21) limits the generation to the installed capacity multiplied by the load factor $\mathrm{LF}_{t, i}^{\mathrm{w}}$. The renewable generator can curtail its output.

\subsubsection{Market coupling operator}

Both markets are coupled through an interconnector, operated by a market coupling operator $M$ who arbitrages perfectly between both countries. Inspired by Hobbs and Helman (2004), we model the market coupling operator as an arbitraging agent with the objective of maximizing its profit from arbitrage, taking into account transmission costs. The decision variables are the energy imported into or exported from each country $a_{t, i}{ }^{6}$, and the flow over the transmission line $f_{t}$. The market coupling operator solves the optimization problem (23)-(25):

$$
\text { Maximize } \sum_{t \in \mathcal{T}}\left(\sum_{i \in \mathcal{I}}\left(\lambda_{t, i} \cdot a_{t, i}\right)-\mathrm{CT} \cdot f_{t}\right)
$$

subject to

$$
\sum_{i \in \mathcal{I}} a_{t, i}=0, \quad \forall t \in \mathcal{T} \quad\left(\rho_{t}\right)
$$

\footnotetext{
${ }^{6}$ If $a_{t, i} \geqslant 0$, country $i$ imports electricity, while a negative $a_{t, i}$ implies export.
} 


$$
f_{t} \geqslant a_{t, i}, \quad \forall t \in \mathcal{T}, i \in \mathcal{I} \quad\left(\sigma_{t, i}\right)
$$

We assume a non-binding transmission capacity and a small linear transmission cost CT in order to give a small location-specific signal for generation and DER investments. Constraint (24) imposes conservation of energy, entailing that the import in one country equals the export from the other country. Equation (25) determines the absolute power flow over the transmission line, which governs the transmission costs.

\subsubsection{Coupling constraints}

The optimization problems of the agents are coupled through the market clearing and cost recovery coupling constraints. The market clearing constraint ensures a balance between the sum of residential and non-residential demand $\left(D_{t, i}^{\text {nres }}\right)$ and the sum of all generation and import at each time step in each country. The wholesale electricity prices that determine the balance are the dual variables $\lambda_{t, i}$ of the constraint. The market clearing constraint is given by Equation (26):

$$
\sum_{k \in \mathcal{K}} g_{t, i, k}^{\mathrm{conv}}+g_{t, i}^{\mathrm{w}}+a_{t, i}=\mathrm{D}_{t, i}^{\mathrm{nres}}+\sum_{j \in \mathcal{J}} \mathrm{N}_{i, j} \cdot w_{t, i, j}, \quad \forall t \in \mathcal{T}, i \in \mathcal{I} \quad\left(\lambda_{t, i}\right)
$$

The cost recovery constraint ensures that the regulated DSOs in each country recover their costs from the residential consumers. The constraint reflects that, in the long-run equilibrium, each DSO sets the distribution tariff $\left(\operatorname{tar}_{i}^{\mathrm{fix}}, \operatorname{tar}_{i}^{\mathrm{nm}}\right.$ or $\left.\operatorname{tar}_{i}^{\mathrm{pd}}\right)$ in such a way that its $\operatorname{costs} c_{i}^{\text {DSO }}$ are exactly recovered. ${ }^{7}$ The distribution tariff structure, determined by the binary parameters $\mathrm{u}_{i}^{\mathrm{fix}}, \mathrm{u}_{i}^{\mathrm{nm}}$ and $\mathrm{u}_{i}^{\mathrm{pd}}$, is set exogenously by the regulator. The constraint contains decision variables of the residential consumers, $w_{i, j}^{\text {net }}$ and $w_{i, j}^{\text {peak }}$, reflecting the reaction of consumers to the tariffs. The cost recovery constraint is given by Equation (27):

$$
\sum_{j \in \mathcal{J}} \mathrm{N}_{i, j} \cdot\left(\mathrm{u}_{i}^{\mathrm{fix}} \cdot \operatorname{tar}_{i}^{\mathrm{fix}}+\mathrm{u}_{i}^{\mathrm{nm}} \cdot \operatorname{tar}_{i}^{\mathrm{nm}} \cdot w_{i, j}^{\mathrm{net}}+\mathrm{u}_{i}^{\mathrm{pd}} \cdot \operatorname{tar}_{i}^{\mathrm{pd}} \cdot w_{i, j}^{\mathrm{peak}}\right)=c_{i}^{\mathrm{DSO}}, \quad i \in \mathcal{I} \quad\left(\phi_{i}\right)
$$

\footnotetext{
${ }^{7}$ We disregard the profit margin allowed by the regulator.
} 
As described in Section 2.1, we consider two cases, regarding network costs:

Sunk network costs - the network costs are fixed:

$$
c_{i}^{\mathrm{DSO}}=\mathrm{C}^{\mathrm{sunk}}
$$

Variable network costs - the network costs are partly sunk $\left(\mathrm{C}^{\text {sunk }}\right)$ and partly proportional to the coincident offtake/injection peak, governed by the incremental network costs $\mathrm{C}^{\text {incr }}$ in $€ / \mathrm{kW}$, following Schittekatte and Meeus $(2018)^{8}$ :

$$
c_{i}^{\mathrm{DSO}}=\mathrm{C}^{\mathrm{sunk}}+\mathrm{C}^{\mathrm{incr}} \cdot \max _{t \in \mathcal{T}}\left(\left|\sum_{j \in \mathcal{J}} N_{i, j} \cdot w_{t, i, j}\right|\right)
$$

\subsection{Solution algorithm}

We compute a Nash equilibrium of the non-cooperative game (2)-(27) following the very general procedure of "tâtonnement" or "trial-and-error" (Uzawa, 1960). It is also possible to compute the equilibrium by solving the mixed complementarity problem reformulation of the game with the PATH solver (Dirkse and Ferris, 1995). However, the latter solution procedure proved to be unstable for large instances.

In the "tâtonnement" approach, price variables, connected to the coupling constraints, are iteratively updated in order to coordinate the agents towards an equilibrium. The dual variables $\lambda_{t, i}$ are the wholesale electricity market prices associated with the market clearing constraint (26). For the cost recovery constraint, we consider the tariffs $\operatorname{tar}_{i}^{\mathrm{fix}}$, $\operatorname{tar}_{i}^{\mathrm{nm}}$ and $\operatorname{tar}_{i}^{\mathrm{pd}}$ as coordinating prices. In each iteration, the prices and tariffs are fed to the optimization problems of all agents, detailed in Sections 2.3.1-2.3.4, who consequently make their decisions. Afterwards, it is checked whether the obtained decisions lead to balanced "markets", i.e., whether the market clearing constraints (26) and the cost recovery constraints (27) are satisfied. If the coupling constraints are not satisfied, the prices and

\footnotetext{
${ }^{8} \mathrm{C}^{\text {incr }}$ can be interpreted as the long-run marginal costs of the distribution network. The simplified linear network function follows from the general assumption that the coincident network peak is the main cost driver of distribution networks in the long-run, as the networks are designed to accommodate peak demand/injection (MIT Energy Initiative, 2016).
} 
tariffs are updated according to the imbalances on the coupling constraints. If the algorithm converges, the solution simultaneously satisfies both coupling constraints (26)-(27), and the optimization problems of residential consumers (2)-(16), conventional generators (17)-(19), renewable generators (20)-(22) and market coupling operator (23)-(25). The solution, though not necessarily unique, is thus a Nash equilibrium of the equilibrium problem (2)-(27).

Our implementation of the "tâtonnement" algorithm is inspired by the Alternating Direction Method of Multipliers (ADMM), more specifically by the implementation of Höschle et al. (2018). ADMM is a dual decomposition method that was originally developed for solving convex optimization problems that are separable in multiple local optimization problems (Boyd et al., 2011). Höschle et al. (2018) solve a long-run power market equilibrium problem with ADMM, showing that their equilibrium problem can be reformulated as an optimal exchange optimization problem, for which ADMM is a well-suited solution approach (Boyd et al., 2011). Höschle et al. (2018) consider the equilibrium between price-taking generators and consumers on an energy market, a capacity market and a renewable certificate market, each represented by a coupling constraint. In Appendix A, we show that the equilibrium problem (2)-(27) can also be reformulated as an optimal exchange problem, following Höschle et al. (2018). Details on the implementation of the ADMM algorithm can be found in Appendix B.

\section{Results}

We analyze the spillover effects of distribution grid tariffs based on a numerical example, described in Section 3.1. In Section 3.2, we present the results, assuming fully sunk network costs, for one proxy for welfare and two proxies for DER investments, in nine distribution tariff scenarios, in order to analyze welfare and DER investment spillovers respectively. Afterwards, we present a sensitivity analysis. Finally, the results assuming variable network costs are presented in Section 3.3. 


\subsection{Numerical example}

\subsubsection{Set-up}

We consider two countries and two consumer segments: active and passive residential consumers in the "reference country" and the "neighboring country". All consumers belonging to the same segment and country are assumed identical. Therefore, all residential consumers are represented by four representative consumers, as described in Section 2.2. Active consumers are able to invest in PV and storage while passive residential consumers are unable to do so. Consumers may be passive for a variety of reasons: they rent so they cannot make the investment decision, they have a limited budget, etc. We assume that each country consists for $50 \%$ of active and $50 \%$ of passive consumers, which we will vary in the sensitivity analysis. Both countries are identical, except for the tariff design which is set by the national regulator.

\subsubsection{Data}

All consumers have identical load profiles $\mathrm{D}_{t, i, j}$, obtained from the 2017 Belgian synthetic load profiles (SLPs) of residential consumers with a yearly demand of $3500 \mathrm{kWh}$ (Synergrid, 2018). Note that synthetic load profiles are average consumer load profiles. Actual consumer load profiles are less smooth and have higher peaks. This will mainly influence the operation and profitability of storage for residential consumers. The investment limits for active consumers $\left(\overline{\mathrm{cap}^{\mathrm{pv}}}\right.$ and $\left.\overline{\mathrm{cap}^{\mathrm{s}}}\right)$ are set at $5 \mathrm{~kW}$ and $10 \mathrm{kWh}$ respectively. Both countries have 4.8 million residential consumers, similar to Belgium. Consequently, both countries have 2.4 million active consumers and 2.4 million passive consumers. The non-residential demand $\mathrm{D}_{t, i}^{\text {nres }}$ is calculated by subtracting the residential demand from the total load profile of the Belgian power system in 2017, provided by the Belgian TSO Elia (Elia, 2018). The annual residential demand in each country equals 16.8 TWh (3500 kWh times 4.8 million consumers), compared to a total system load of 87.1 TWh. The system load peak is 13.1 GW. The wind and PV load factors $\mathrm{LF}_{t, i}^{\mathrm{w}}$ and $\mathrm{LF}_{t, i}^{\mathrm{pv}}$ are obtained by normalizing the output of the Belgian solar PV and wind turbines in 2017 by the installed capacity, both of which are provided by Elia (Elia, 2018). All simulations are performed on a set of 12 representative 
days, i.e., 12 weighted time series of 24 hours, of the year 2017, selected via the method of Poncelet et al. (2017). ${ }^{9}$

In the sunk cost case, in order to recover their sunk costs, each DSO needs to recover $€ 400$ from each consumer on average. ${ }^{10}$ For the variable cost case, we divide this cost in an endogenous and exogenous part following D'hulst et al. (2018). The endogenous costs, related to the investment in and operation of the network, contribute to approximately $40 \%$ of the total DSO costs in Flanders. Dividing these costs by the coincident peak demand of $0.8 \mathrm{~kW}$ per consumer leads to an incremental network cost $\mathrm{C}^{\text {incr }}$ of $200 € / \mathrm{kW}$. The exogenous costs are mainly related to policy costs and contribute to $60 \%$ of the total costs. They are thus equal to $€ 240$ per consumer on average.

There is no utility scale PV, i.e., all PV is installed by residential consumers. The installation cost of PV is assumed to be $1000 € / \mathrm{kW}$ with a lifetime of 20 years and a discount rate of $5 \%$. This cost assumption is lower than most estimates of current costs, but as the costs are still decreasing rapidly they are realistic for the near future, especially in Europe. The cost of residential PV up to $5 \mathrm{~kW}$ reached $1790 € / \mathrm{kW}$ in Q2 of 2016 in Germany, for instance, coming down from $4500 € / \mathrm{kW}$ in 2010 (IRENA, 2017b). For PV systems between 5 and $10 \mathrm{~kW}$, the cost in 2016 was already down to $1550 € / \mathrm{kW} .{ }^{11}$ Similar to PV, we assume storage is only installed by residential consumers. The installation cost of storage is assumed to be $200 € / \mathrm{kWh}$ with a lifetime of 10 years and a discount rate of $5 \%$. This cost is in line with the low estimates for 2030 (IRENA, 2017a). We assume that

\footnotetext{
${ }^{9}$ Poncelet et al. (2017) develop an optimization problem which allows selecting a number of days, along with weights ascribed to each day, that are representative for a whole year. The optimization problem minimizes the difference between the actual duration curve and the approximated duration curve constructed using the selected days, taking into account the weight of each day. The optimization problem can take into account multiple time series. We took into account the load curves of residential consumers, the total system load curve, the wind load factor curve and the solar load factor curve.

${ }^{10}$ The distribution costs of the average consumer in Flanders in 2017 were $€ 393$ (VREG, 2017).

${ }^{11}$ In the United States, on the other hand, the costs are significantly higher: $5040 € / \mathrm{kW}$ for PV systems up to $5 \mathrm{~kW}$ and $4600 € / \mathrm{kW}$ for PV systems between 5 and $10 \mathrm{~kW}$ (IRENA, 2017b). These costs are also rapidly decreasing however.
} 
each storage system can be fully charged or discharged in 1 hour, i.e., their C-rate is equal to $1 \mathrm{MW} / \mathrm{MWh}$. The charging and discharging efficiency are both $95 \%$.

Table 1: Variable and annualized investment costs of the considered conventional generation technologies, obtained from Höschle et al. (2018).

\begin{tabular}{ccc} 
Technology & Variable cost $\mathrm{VC}_{k}(€ / \mathrm{MWh})$ & Annualized investment cost $\mathrm{IC}_{k}^{\text {conv }}(€ / \mathrm{MW})$ \\
\hline Base & 36 & 138000 \\
Mid & 53 & 82000 \\
Peak & 76 & 59000 \\
\hline
\end{tabular}

All generation besides PV is installed at transmission level. For centralized generation, we use the data of Höschle et al. (2018). There is one renewable generation technology at the transmission level: wind. It has an annualized investment cost of $76500 € / \mathrm{MW}$ and no variable cost. There are three conventional generation technologies, i.e., base-, mid- and peak-load generation. The variable and investment costs of these generation technologies are presented in Table 1. Technical constraints, e.g., ramping, are not taken into account.

As discussed in Section 2.1, there is one transmission line between both countries with a non-binding capacity and a small transmission cost. We set $\mathrm{CT}=0.001 € / \mathrm{MWh}$, which is large enough to give a location-specific investment signal, but does not distort other investment incentives, i.e. distribution tariffs.

\subsection{Sunk network costs}

In this section, we discuss the spillover effects in the reference country $(\mathrm{R})$, of distribution grid tariffs in the neighboring country $(\mathrm{N})$, based on three proxies for nine distribution tariff scenarios, under sunk network costs. The nine scenarios follow from the disjoint implementation of three distribution tariff structures in both countries: a fixed tariff structure (FIX), a volumetric tariff structure with net-metering (NM) and a peak demand-based tariff structure (PD). We distinguish two types of spillovers: 1) welfare spillovers, 2) DER investment spillovers. Figure 2 (on the left y-axis) presents the total annual cost increase of residential consumers in the reference country compared to a central planner reference scenario, serving 
as proxy for welfare. ${ }^{12}$ The total annual costs are the sum of energy, distribution and annualized investment costs of all active and passive consumers in the reference country. Note that the total distribution costs in a country cannot change due to the sunk cost assumption, implying that the changes in costs only reflect changes in energy and investment costs. To reflect this, we scale the right y-axis so that the markers also indicate the increase in energy and investment costs of residential consumers in the reference country compared to a central planner reference. Comparing the scales of both axes shows that the sunk distribution costs dampen the total cost spillovers.

Figures 3 and 4 (on the left y-axes) present the total installed PV and storage capacities in the reference country, visualizing the DER investment spillover. The right y-axes are scaled so that the markers in Figures 3 and 4 also indicate the investments per active consumer in the reference country. The shaded areas in the figures group the three scenarios for which the tariff design in the reference country is the same. In each shaded area, there is one harmonized tariff scenario (in which both countries impose the same tariff design), serving as reference, and two unharmonized tariff scenarios (in which the neighboring country imposes a different tariff design). The welfare and DER investment spillovers in the reference country, of unharmonized distribution tariffs in the neighboring country, are found by comparing the scenarios with unharmonized tariffs to the harmonized tariff scenario within each shaded area. In Sections 3.2.1-3.2.3, we discuss the results of each shaded area separately. The sensitivity of these results to a number of relevant parameters is analyzed in Section 3.2.4.

\subsubsection{Fixed tariff in the reference country}

We make three observations from Figures 2-4 (shaded, pink areas). First, concerning welfare, the spillover effects of the neighboring country moving from a fixed tariff structure towards a net-metering or peak demand-based tariff structure are positive (Fig. 2). Second, PV investment is not impacted by the tariff design in the neighboring country (Fig. 3).

\footnotetext{
${ }^{12}$ The central planner reference scenario refers to the "optimal" long-run equilibrium state of the electricity system that would be obtained by a social welfare maximizing central planner. Note that the central planner scenario corresponds to the scenario with a fixed tariff in both countries as we discuss in Section 3.2.1.
} 


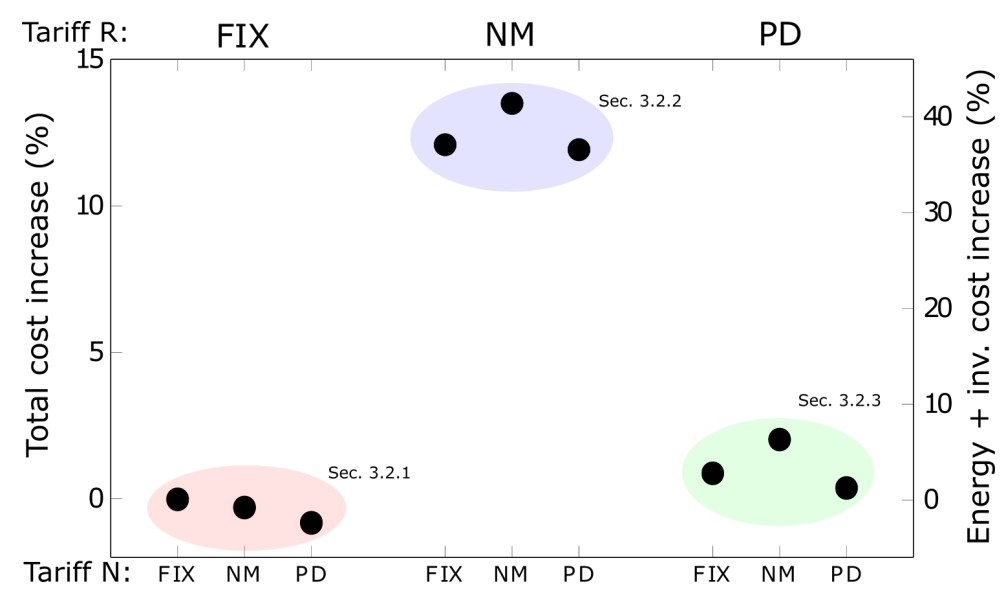

Figure 2: Increase of total (left y-axis) and energy + investment (right y-axis) annual costs of residential consumers in the reference country $(\mathrm{R})$ compared to a central planner reference case.

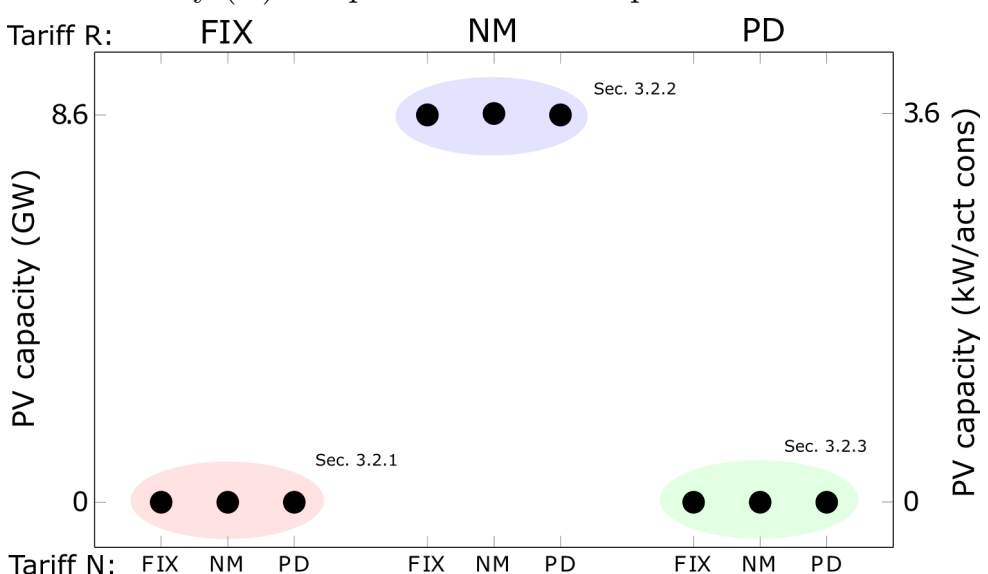

Figure 3: Total PV investment by residential consumers in the reference country (R) (left y-axis) and PV investment per active consumer in $\mathrm{R}$ (right $\mathrm{y}$-axis).

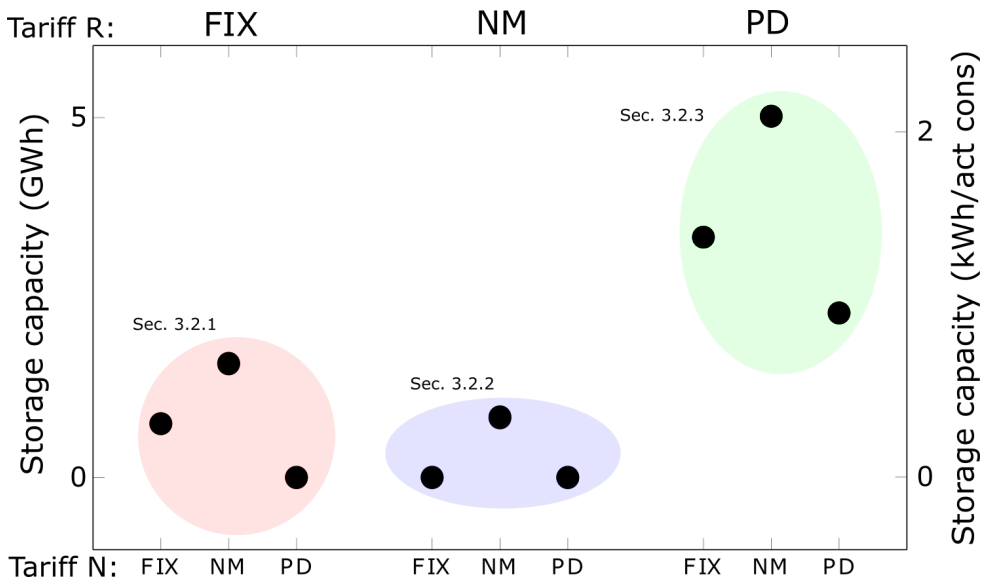

Figure 4: Total storage investment by residential consumers in the reference country (R) (left y-axis) and storage investment per active consumer in $\mathrm{R}$ (right $\mathrm{y}$-axis). 
Third, storage investment increases when the neighboring country imposes a net-metering tariff and decreases when the neighboring country imposes a peak demand-based tariff (Fig. 4). We discuss these observations for each tariff scenario separately in the following three paragraphs.

Fixed tariff in neighboring country. As indicated in Figure 2, the scenario with harmonized distribution grid tariff structures corresponds to the central planner reference scenario. This results from the set-up of the model, i.e., representing an idealized electricity market, and the sunk cost assumption. Under this assumption, the total distribution network $\operatorname{costs} c_{i}^{\mathrm{DSO}}$ can never be lowered which implies that only energy cost savings justify DER investment from a social welfare perspective. Under a fixed distribution tariff, active consumers cannot lower their distribution costs which implies that they only invest in PV and/or storage if the subsequent energy cost savings outweigh the investment costs. This leads to the optimal outcome from a social welfare perspective, disregarding other market imperfections. Under our cost assumptions, PV is never installed in the reference country under a fixed distribution tariff (Fig. 3). Storage investment is limited, equalling 0.8 GWh in the scenario with harmonized tariffs. The storage systems are used to perform price arbitrage on the wholesale market.

Peak demand-based tariff in neighboring country. Compared to the previous scenario with harmonized distribution tariff structures, the costs of residential consumers in the reference country decrease with $0.8 \%$ (Fig. 2). The peak demand-based tariff incentivizes storage investment in the neighboring country (not visible in Fig. 4) because it allows active consumers to decrease their peak consumption/injection. The extra storage investment in the neighboring country is not only used for reducing peak consumption/injection, but also for price arbitrage. Arbitrage decreases the price spreads on the wholesale market. It leads to lower energy costs for passive consumers in the reference country because it reduces demand-weighted average wholesale electricity prices. At the same time, it reduces the arbitrage potential of storage because arbitrage is incentivized by price spreads. This results in active consumers in the reference country not investing in storage (Fig. 4). The 
subsequent investment cost savings outweigh the energy cost increase of active consumers. Consequently, the total annual costs of both active and passive consumers in the reference country decrease.

Net-metering tariff in neighboring country. Due to the volumetric tariff structure with netmetering, active consumers in the neighboring country are incentivized to invest in $8.6 \mathrm{GW}$ of PV in total (not visible in Fig. 3), because PV production lowers the net consumption of residential consumers. This massive PV investment only results in a small positive spillover in terms of social welfare in the reference country, i.e., the costs of residential consumers are $0.3 \%$ lower than in the harmonized tariff scenario (Fig. 2). This result is confirmed by the work of, e.g., Usaola et al. (2009) and Green and Vasilakos (2011), who find that wholesale prices are not heavily impacted by the increasing penetration of RES in the longrun equilibrium, as the production park can adapt to the changed residual demand curve. The PV investment in the neighboring country leads to increased storage investments in the reference country, now totalling 1.6 GWh (Fig. 4), because PV increases the price spreads between high- and low-price hours and consequently the arbitrage potential of storage.

\subsubsection{Volumetric tariff with net-metering in the reference country}

Similar to the previous section, we make three observations from Figures 2-4 (shaded, blue areas). First, the welfare spillovers of the neighboring country moving towards a (unharmonized) fixed or peak demand-based tariff are positive (Fig. 2). Second, there are no PV investment spillovers (Fig. 3). Third, there are negative storage investment spillovers,

i.e., storage is only installed when both countries impose a net-metering tariff structure (Fig. 4). Similar to the previous section, we dedicate one paragraph to each tariff scenario, discussing our three observations.

Net-metering tariff in neighboring country. When the NRAs in both countries impose volumetric net-metering tariffs, active consumers in both countries invest in $3.6 \mathrm{~kW}$ of PV each, resulting in a total of $8.6 \mathrm{GW}$ in the reference country (Fig. 3). This allows active consumers to generate sufficient energy on an annual basis to avoid all distribution costs, 
i.e., the annual net consumption of each active consumers is zero. This PV investment is inefficient from a social planner perspective because the avoided distribution costs are merely transferred to passive consumers through increased distribution tariffs. As a result, the total costs of residential consumers in the reference country are $13.5 \%$ higher than in the central planner reference (Fig. 2). A net-metering tariff disincentivizes storage investment because the losses in the storage system increase the net consumption. In the harmonized tariff scenario, however, active consumers in the reference country install $0.8 \mathrm{GWh}$ of storage because the cost reductions arising from price arbitrage outweigh the efficiency losses (Fig. $4)$.

Fixed tariff in neighboring country. In this scenario, the installed PV capacity in the neighboring country decreases to zero. The PV investment in the reference country, however, remains 8.6 GW since it allows the active consumers to shift all their distribution to the passive consumers (Fig. 3). The storage investment in the reference country decreases to zero (Fig. 4). All 1.6 GWh of storage is now installed in the neighboring country because a fixed distribution tariff does not disincentivize storage like a volumetric net-metering tariff does. The total cost increase of residential consumers in the reference country compared to the central planner reference decreases to $12.1 \%$ (Fig. 2). This positive welfare spillover in the reference country is explained by two factors impacting only active consumers: a decrease of storage investment and an increase of the market value of PV, defined as the average electricity price weighted for PV production (Hirth, 2013). Hirth (2013) shows empirically, and through numerical modeling, how the market value of PV decreases with increasing PV penetration, defined as the share of PV production in the total amount of produced electricity. This follows from the merit-order effect which entails that more zero marginal cost PV production during a certain time step leads to lower wholesale prices at that time step. In the harmonized tariff scenario, 8.6 GW of PV is installed in each country resulting in a PV penetration of $9.6 \%$ and a market value of $35.6 € / \mathrm{MWh}$. If the neighboring country imposes a fixed distribution tariff, the PV penetration decreases to $4.8 \%$, resulting in a market value of $40.3 € / M W h$. Resulting from the increase in market value and the decrease 
in storage investment, the costs of active consumers in the reference country decrease from $354.7 € /$ year/consumer in the harmonized tariff scenario to $338.0 € /$ year/consumer in the scenario with a fixed tariff in the neighboring country. The costs of passive consumers, however, do not change as the PV investment does not impact the average wholesale electricity prices in the long-run (cf. Section 3.2.1). Under a net-metering tariff, the positive welfare spillovers are thus for the active consumers while there is no impact on passive consumers.

Peak demand-based tariff in neighboring country. In this scenario, the positive welfare spillovers are larger than in the previous scenario: the cost increase of residential consumers in the reference country compared to the central planner reference is $11.9 \%$ instead of $12.1 \%$. The extra storage investment in the neighboring country (5 GWh under a peak demandbased tariff compared to 1.6 GWh under a fixed tariff), increases the market value of PV (from $40.3 € / \mathrm{MWh}$ to $40.6 € / \mathrm{MWh}$ ) and decreases the average wholesale electricity price weighted for the demand of passive consumers (from $54.7 € / \mathrm{MWh}$ to $54.6 € / \mathrm{MWh}$ ). Both active and passive consumers in the reference country thus profit from the extra storage investment in the neighboring country, although the impact is limited to $0.2 \mathrm{pp}$.

\subsubsection{Peak demand-based tariff in the reference country}

We again make three observations from Figures 2-4 (shaded, green areas). We then devote one paragraph to each tariff scenario, discussing these observations. First, the welfare spillovers of an unharmonized tariff structure (a fixed or volumetric net-metering tariff in the neighboring country) are negative (Fig. 2). Second, there is no PV investment in any scenario (Fig. 3). Third, storage investment increases when the neighboring country imposes an unharmonized tariff structure (Fig. 4).

Peak demand-based tariff in neighboring country. In the harmonized tariff scenario, the storage investment in the reference country equals 2.3 GWh (Fig. 4), while there is no PV investment because PV does not allow reducing the peak consumption that occurs during winter evenings in Belgium (Fig. 3). The cost increase for residential consumers compared to the central planner reference is $0.4 \%$ (Fig. 2). The storage investment, and the resulting 
consumer costs, depend on how active consumers utilize their storage systems. On one hand, active consumers perform price arbitrage, which lowers the total costs for consumers and disincentivizes further storage investments as the arbitrage potential decreases. On the other hand, active consumers use storage to lower their peak demand, subsequently transferring distribution costs to passive consumers, incentivizing further storage investments as the distribution tariffs increase. Both activities can be carried out by the same storage system, but consumers always make a trade-off. ${ }^{13}$ In this scenario, we observe a limited amount of storage investment and a limited cost increase for residential consumers in the reference country, implying that the inefficient non-cooperative behavior of active consumers is limited.

Fixed tariff in neighboring country. Compared to the harmonized tariff scenario, the storage investments in the neighboring country decrease. The subsequent increased arbitrage potential of storage results in an increased storage investment of $3.3 \mathrm{GWh}$ in the reference country (Fig. 4). The total cost increase of residential consumers in the reference country also increases to $0.9 \%$ (Fig. 2), i.e., there are negative spillovers. This implies that active consumers use the extra storage capacity to transfer more distribution costs to passive consumers. Indeed, we observe that the $50 \%$ passive consumers now pay $56.6 \%$ of the total distribution costs compared to $56.0 \%$ in the harmonized tariff scenario. Note that the scenarios with a peak-demand tariff in the reference country are the only scenarios in which the spillovers also impact the distribution of network costs between active and passive consumers. ${ }^{14}$

Net-metering tariff in neighboring country. We observe the same effects as in the previous scenario, but they are more pronounced. The storage investment in the reference country is 5.0 GWh (Fig. 4) and the total cost increase is $2.0 \%$ (Fig. 2), as passive consumers pay $57.5 \%$ of the total distribution costs. The net-metering tariff in the neighboring country

\footnotetext{
${ }^{13}$ This trade-off is reflected in the objective function (2) of the consumers' optimization problems, in which they minimize the sum of their investment, distribution and energy costs.

${ }^{14}$ Under a fixed tariff, distribution costs cannot be shifted, while active consumers avoid all distribution costs in each net-metering tariff scenario (cf. Section 3.2.2).
} 
initially increases the arbitrage potential of storage more than a fixed tariff, because it induces PV investment in the neighboring country, leading to increased wholesale market price spreads. This leads to increasing storage investment and a worse manifestation of the non-cooperative behavior of consumers in the reference country, i.e., active consumers use this extra storage capacity to transfer more distribution costs to passive consumers.

\subsubsection{Sensitivity analysis}

We compare the base case to six other cases. The six cases differ from the base case as follows, ceteris paribus:

1. The DSO costs are decreased from $400 € /$ cons/y tot $200 € /$ cons/y.

2. The share of active consumers in the neighboring country is $25 \%$ instead of $50 \%$.

3. The share of active consumers in the reference country is $25 \%$ instead of $50 \%$.

4. The size of the neighboring country, regarding amount of residential consumers and non-residential demand, is increased with a factor of 5 .

5. The size of the reference country is increased with a factor of 5 .

6. The annual demand per residential consumer increases from $3500 \mathrm{kWh}$ to $5000 \mathrm{kWh}{ }^{15}$

Constructed similarly to Figures 2 and 4, Figures 5 and 6 allow comparing the welfare and storage investment spillovers of the aforementioned six cases with the base case. Note that Figure 6 only presents the storage investment per active consumer in the reference country. ${ }^{16}$ The PV investments are not presented as there are no PV investment spillovers in any case. ${ }^{17}$

For a fixed tariff in the reference country, the welfare spillovers barely differ. The storage spillovers are also similar for all cases. The storage investment only increases when the

\footnotetext{
${ }^{15}$ This increases the share of residential demand from $19 \%$ to $28 \%$ of the total demand.

${ }^{16}$ This facilitates the comparison as the amount of active consumers is not the same in all cases.

${ }^{17}$ The PV investments are exactly the same as in the base case, except for case 6 in which the residential demand increases. In that case, active consumers invest in $5 \mathrm{~kW}$ each instead of $3.6 \mathrm{~kW}$ under a net-metering tariff in order to reduce their net consumption.
} 


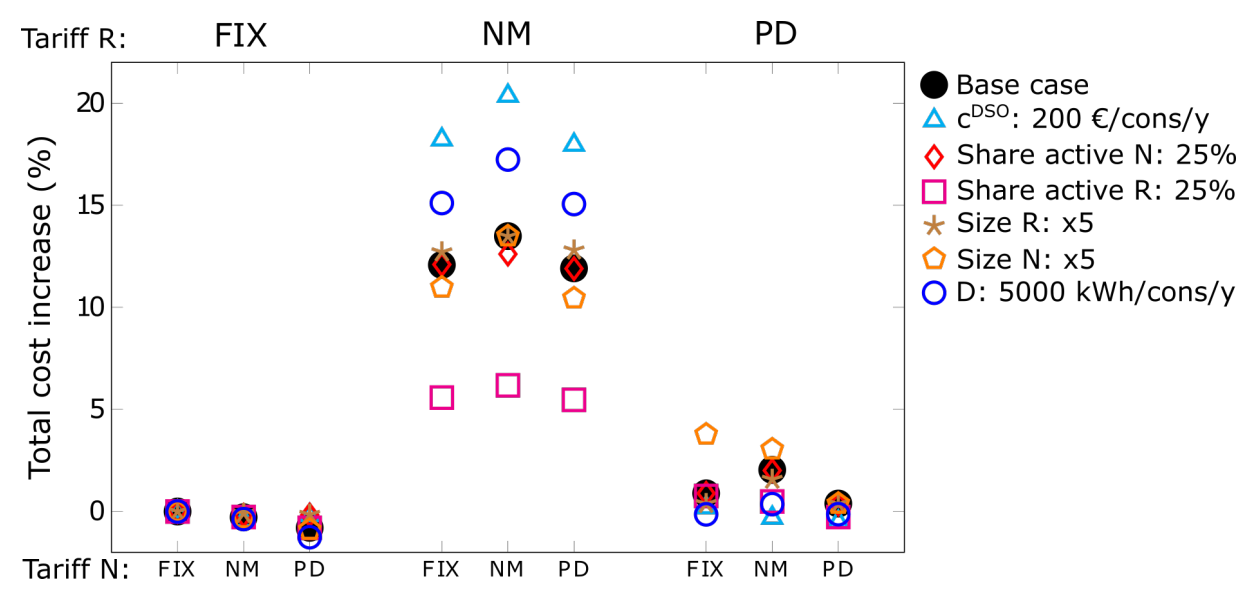

Figure 5: Increase of total annual costs of residential consumers in the reference country (R) compared to a central planner reference case.

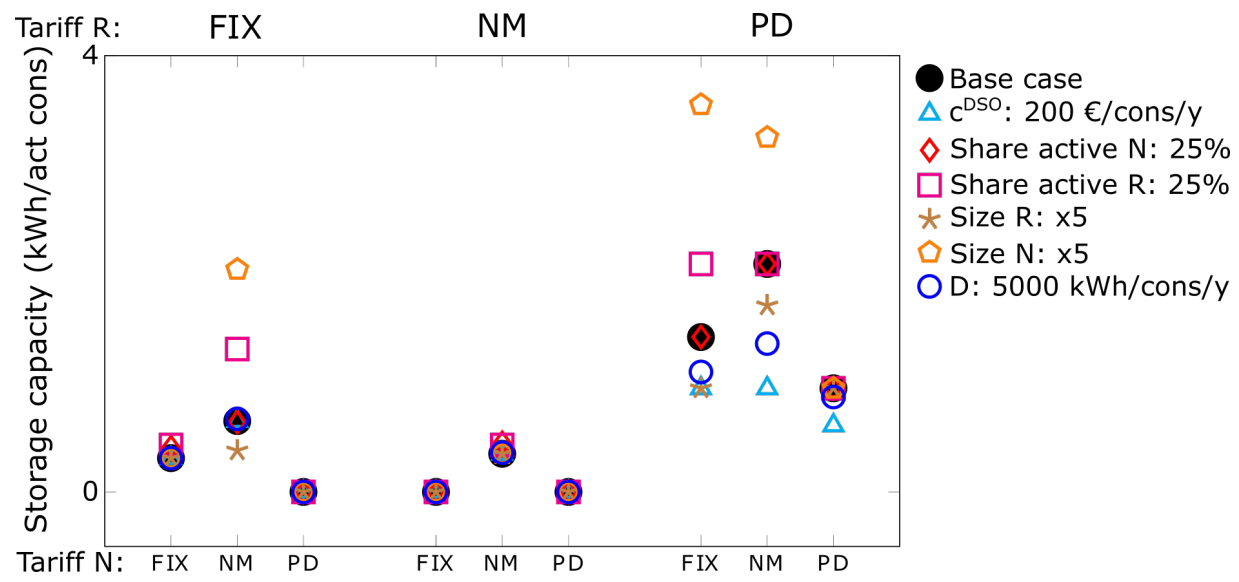

Figure 6: Storage investments per active residential consumer in the reference country (R).

neighboring country increases in size or the amount of residential consumers in the reference country decreases, while it decreases if the reference country increases in size. These differences are caused by changes to the arbitrage potential of storage, as discussed in Section 3.2.3. If the neighboring country increases in size, for instance, the arbitrage potential of storage does not decrease as rapidly with increased storage investment in the reference country due to the increased size of the combined wholesale market.

For a net-metering tariff in the reference country, the cost increases compared to the central planner reference differ significantly between scenarios. The welfare spillovers, however, derived by comparing the markers for each case, remain roughly the same. Compared to 
the base case, they slightly increase when the distribution costs decrease, the neighboring country increases in size and the residential demand increases. They slightly decrease when the share of active consumers in either country decreases and when the reference country increases in size. The differences in storage investment spillovers are negligible.

For a peak demand-based tariff in the reference country, the welfare and storage investment spillovers differ the most between cases. The order of magnitude of the welfare spillovers and their direction, i.e., negative spillovers or cost increases when moving towards an unharmonized tariff structure, remain the same, but in most cases the spillovers decrease compared to the base case. They only increase when the neighboring country increases in size. The storage investment spillovers also typically decrease compared to the base case. They only increase when the neighboring country increases in size or the amount of active consumers in the reference country decreases. In contrast to the base case, a net-metering tariff in the neighboring country does not lead to higher costs than a fixed tariff in three cases ( $c^{\mathrm{DSO}}: 200 € /$ cons/y; share active R: $25 \%$; size N: $\mathrm{x} 5$ ). This results from the complex trade-off embedded in the objectives of residential consumers, who minimize both energy and distribution costs. In the base case (Section 3.2.3), we observe that increased arbitrage potential leads to more storage investment which active consumers use to further reduce their distribution costs, increasing the total costs as the distribution costs are merely shifted towards passive consumers. In the aforementioned cases, the increased arbitrage potential of storage incentivizes consumers in the reference country to focus more on arbitrage instead of peak reduction, thereby decreasing total costs.

\subsection{Variable network costs}

In this section, we present a first analysis of the spillover effects of distribution tariffs under variable network costs. Figure 7 presents the relative energy and investment costs (red circles, right y-axis) in each distribution tariff scenario compared to the harmonized fixed tariff scenario. ${ }^{18}$ Comparing Figures 2 (right y-axis) and 7 (red circles, right y-axis), we find that the spillovers of energy and investment costs are nearly identical in both the variable and

\footnotetext{
${ }^{18}$ With variable network costs, this scenario does not correspond to the central planner reference.
} 
sunk network cost cases. In fact, the energy and investment costs of consumers are identical in most scenarios. Only in the FIX (in R) - PD (in N) and PD-NM scenarios we observe small differences: 0.7 and 1.2 pp respectively, translating to differences of approximately 0.3 and $0.4 \mathrm{pp}$ in total costs. In addition, we find that PV and storage investments are identical, implying that Figures 3 and 4 remain valid in the variable cost case. ${ }^{19}$ We thus conclude that the insights gained in Section 3.2, concerning DER investment and welfare spillovers, caused by changing energy and investment costs, are also valid under variable network costs.

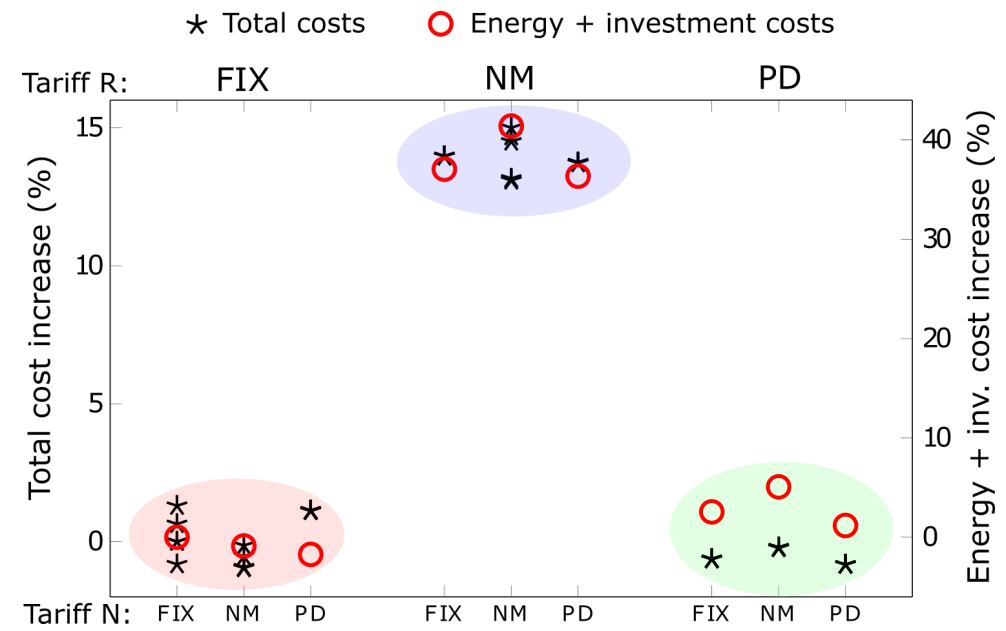

Figure 7: Increase of total (black stars, left y-axis) and energy + investment (red circles, right y-axis) annual costs of residential consumers in the reference country $(\mathrm{R})$ compared to one FIX-FIX reference case.

In contrast to the sunk cost case however, distribution costs may change between scenarios, thereby impacting the welfare spillovers. Figure 7 also presents the total annual consumer costs (black stars, left y-axis) in each distribution tariff scenario, relative to a harmonized fixed tariff scenario. In some scenarios there exist multiple equilibria, with different costs for consumers. Five equilibria are presented in Figure $7 .^{20}$

\footnotetext{
${ }^{19}$ The small differences in costs we observed in two scenarios are caused by the impact of the changing tariff level on the trade-off between minimizing distribution and energy costs under a peak demand-based tariff as described in Section 3.2.3.

${ }^{20}$ The methodology used to obtain multiple equilibria is described in Appendix B.5. The equilibrium in the harmonized fixed tariff scenario with the median consumer costs is chosen as reference. Note that we do
} 
As the energy and investment costs barely differ between multiple equilibria ${ }^{21}$, the variation in costs is solely explained by a variation in distribution network costs. This variation in network costs is caused by different storage operation strategies, which lead to the same energy cost savings, but different coincident peak demands. Consider, for instance, two consecutive hours in which the wholesale electricity price is zero. Assuming that active consumers can fully charge their storage systems in one hour, they could charge during either the first or second hour. Both scenarios will lead to the same arbitrage benefits, but depending on the load profiles of the consumers, the total net offtake will differ. This mechanism occurs in scenarios in which i) consumers own storage and ii) the peak demand of consumers does not impact their distribution costs. The multiple equilibria are thus visibly different in the three scenarios with a fixed or net-metering tariff in the reference country, in which consumers own storage (Fig. 4). Under a peak demand-based tariff, consumers are incentivized to minimize their peak offtake/injection. Hence, the coincident peak will not vary as strongly as in the other cases between different equilibria.

The welfare spillovers under variable network costs (Fig. 7, black stars, left y-axis) have the same order of magnitude as the spillovers under sunk network costs (Fig. 2), but their direction, i.e., whether they are positive or negative, may differ. The existence of multiple equilibria makes the outcome harder to interpret in the case of variable network costs. A probabilistic approach considering heterogeneous consumers, along with a more detailed network cost function, could provide more detailed insights on cost spillovers under variable network costs. Indeed, due to the implementation of a simplified network cost function, along with homogeneous representative consumers, the network costs in the longrun equilibrium are determined by the coincident offtake/injection peak of two consumers, active and passive, in a single hour.

not show all equilibria, nor say anything about the probability of occurrence. Note also that the equilibria coincide in many scenarios.

${ }^{21} \mathrm{We}$ observe variations up to $0.1 \mathrm{pp}$. 


\section{Conclusions and policy implications}

In this paper, we analyzed the spillover effects of distribution grid tariffs in neighboring countries with coupled wholesale markets. We quantified these effects, complementing the insights of other researchers on the direct effects of distribution grid tariffs, e.g. (Schittekatte et al., 2018; Abdelmotteleb et al., 2018). To this end, we developed a novel market equilibrium model which captures the wholesale market effects of distribution grid tariffs. In a case study, we studied the long-run market equilibrium in nine scenarios, spanning all combinations of three distinct distribution grid tariff designs (a tariff consisting of a fixed charge, a tariff consisting of a volumetric charge with net-metering and a tariff consisting of a peak demand charge) in two countries. We compared the costs of residential consumers and DER investments in different scenarios in order to study the welfare and DER investment spillovers respectively. Assuming sunk network costs, our main findings are the following:

1. Concerning welfare, there are positive spillovers in a country that imposes a fixed or net-metering tariff when the neighboring country imposes a different, unharmonized tariff structure. In our case study, the total costs of residential consumers compared to a central planner reference decrease up to $-1.6 \mathrm{pp}$ in the base case. The welfare spillover from an unharmonized tariff structure is negative in a country that imposes a peak demand-based tariff. The total costs of residential consumers compared to a central planner reference increase up to $+1.6 \mathrm{pp}$ in the base case. A sensitivity analysis showed that the direction and order of magnitude of the welfare spillovers remain the same in all analyzed cases, but that the magnitude may differ. In the most extreme case, when the neighboring country increases in size by a factor of five, the welfare spillovers in the neighboring country increase up to $3.5 \mathrm{pp}$.

2. Concerning PV investment, there are no spillover effects. Under a fixed or a peak demand-based tariff, there are no PV investments, because PV is not economically viable from a wholesale market perspective under our cost assumptions. Under a net-metering tariff, active consumers massively invest in PV in order to achieve an 
annual net consumption of exactly zero, thereby shifting all distribution costs to passive consumers, but this incentive is not impacted by wholesale market effects.

3. Concerning storage investment, there are clear spillover effects of which the direction and magnitude differ widely between different scenarios. In the most extreme scenario of our base case, i.e., a peak demand-based tariff, the total storage investment varies from 2.3 GWh to 5.0 GWh. Storage investment always depends on the arbitrage potential on the wholesale market. Under a peak demand-based tariff, consumers also use storage for peak reduction which results in a trade-off between arbitrage and peak reduction. This trade-off leads to different results depending on the setting as our sensitivity analysis showed.

These findings indicate that there can be significant positive and negative welfare spillovers of unharmonized distribution tariff structures in coupled wholesale markets. Under variable network costs, the spillover effects concerning energy and annualized investment costs, as well as DER investments, remain the same. Due to the added impact of distribution cost spillovers, the overall welfare spillovers may change direction, but their order of magnitude remains the same.

Welfare spillovers are thus not a clear argument for harmonization as a country may be better off with unharmonized tariffs. However, it is important to note that the positive welfare spillovers in one country always follow from - from a system perspective - inefficient DER investments in the neighboring country. This has two implications. First, the total welfare in both countries does not necessarily increase. Second, these inefficient DER investments are the result of distribution grid tariffs implicitly subsidizing DERs, which may be seen as a form of state aid, i.e., another argument for harmonization. Implicit DER subsidies in one country also impact DER investments in the other country. We observe, for instance, less storage investment in the reference country when the neighboring country imposes peak demand-based tariffs, serving as implicit subsidies for storage in the neighboring country.

We focused on the impact of distribution tariffs on DER investments and consumer welfare, while ensuring cost recovery for DSOs. In practice, however, tariff design is a 
compromise between a multitude of design principles, e.g. cost reflectivity, cost recovery, simplicity, fairness, etc. (CEER, 2017). It is not straightforward to determine the relative importance of these principles. This strengthens the case of the stakeholders that cite "local specificities" as an argument against harmonization, as one country may assign more importance to a certain principle than another country. Therefore, we do not claim to provide a final answer on the question of harmonization of distribution grid tariffs. However, we are the first to quantify some of the elements which are important in this discussion, i.e., welfare and DER investment spillovers. Note that, although this work is inspired by regulatory discussions in Europe, our conclusions on spillovers are more widely applicable. Similar effects may occur in the USA for instance, as electricity distribution is regulated at state level, while independent system operators often cover multiple states.

In the variable cost case, multiple equilibria with significantly different consumer costs exist due to the deterministic nature of the model, the linear network cost function and the use of homogeneous representative consumers. Therefore, in future work, it would be interesting to address the aforementioned limitations in order to provide more insight in the distribution cost spillovers. Further, we could relax one or more of the assumptions that allows us to model an idealized market, e.g., non-binding transmission capacity, no renewable subsidies, etc. This would give insights in the interaction between the distribution tariff design and other market imperfections. Our analysis can also be extended by including more scenarios with different distribution tariff structures, country sizes, cost parameters, etc. For instance, while there are no PV investment spillovers in any of the analyzed scenarios, we would expect to see spillovers under volumetric tariffs with shorter net-metering periods, e.g., daily instead of yearly. These tariffs would still incentivize PV, but they would not strongly incentivize a specific level of PV investment like a yearly net-metering tariff does. We could also have a closer look at fairness issues by separately analyzing the costs of active and passive consumers. Another direction for future work is to look at the short- and medium-term spillover effects. This would require significant additions to the model with generation capacity being fixed for a certain amount of time, instead of assuming a complete greenfield as we did in this work. 


\section{Acknowledgment}

The research of Niels Govaerts is supported by a PhD grant provided by the Flemish Institute for Technological Research (VITO). Kenneth Bruninx is a post-doctoral research fellow of the Research Foundation - Flanders (FWO) and the Flemish Institute for Technological Research (VITO).

\section{Bibliography}

Abdelmotteleb, I., Gómez, T., Chaves Ávila, J. P., Reneses, J., 2018. Designing efficient distribution network charges in the context of active customers. Applied Energy 210, 815-826.

Borenstein, S., 2016. The economics of fixed cost recovery by utilities. The Electricity Journal 29 (7), 5-12.

Boyd, S., Parikh, N., Chu, E., Peleato, B., Eckstein, J., et al., 2011. Distributed optimization and statistical learning via the alternating direction method of multipliers. Foundations and Trends in Machine Learning $3(1), 1-122$.

Brown, D. P., Sappington, D. E., 2017. Designing compensation for distributed solar generation: Is net metering ever optimal? Energy Journal 38 (3), 1-32.

Brown, D. P., Sappington, D. E., 2018. On the role of maximum demand charges in the presence of distributed generation resources. Energy Economics 69, 237-249.

CEDEC, 2017. Recommendations for the clean energy package. http://cedec.com/files/default/ 170612-cedec-position-clean-energy-for-all.pdf.

CEER, 2017. Distribution and transmission network tariffs and incentives. CEER white paper series on the European Commission's Clean Energy Proposals. https://www.ceer.eu/ documents/104400/5937686/Distribution+and+Transmission+Network+Tariffs+and+Incentives/ 7b52b947-d1b9-7634-aaa0-a865cd856dac.

CEER, 2017. Electricity distribution network tariffs. CEER guidelines of good practice. https://www. ceer . eu/documents/104400/-/-/1bdc6307-7f9a-c6de-6950-f19873959413.

D'hulst, R., Delnooz, A., Laes, E., Six, D., 2018. Onderzoek naar de tariefstructuur van de periodieke distributienettarieven. https://www.vreg.be/sites/default/files/20180111_studie_vreg_ statusrapport_v11_-_eindrapport.pdf.

Dirkse, S. P., Ferris, M. C., 1995. The path solver: a nommonotone stabilization scheme for mixed complementarity problems. Optimization Methods and Software 5 (2), 123-156.

Ehrenmann, A., Smeers, Y., 2011. Generation capacity expansion in a risky environment: A stochastic equilibrium analysis. Operations Research 59 (6), 1332-1346. 
Eid, C., Reneses Guillén, J., Frías Marín, P., Hakvoort, R., 2014. The economic effect of electricity netmetering with solar PV: Consequences for network cost recovery, cross subsidies and policy objectives. Energy Policy 75, 244-254.

Elia, 2018. Data download. http://www.elia.be/nl/grid-data/data-download, (accessed: 17/07/2018). Eurelectric, 2017. European Commission's proposal for a Regulation on the internal market for electricity. A Eurelectric position paper. https://www.eurelectric.org/media/2436/eurelectric_ positionpaper_electricity_regulation_final-2017-030-0241-01-e.pdf.

European Commission, 2016. Proposal for a regulation of the european parliament and of the council on the internal market for electricity. $\operatorname{com}(2016) 861$ final. https://eur-lex.europa.eu/resource.html?uri= cellar:d7108c4c-b7b8-11e6-9e3c-01aa75ed71a1.0001.02/D0C_1\&format=PDF.

Gabriel, S. A., Conejo, A. J., Fuller, J. D., Hobbs, B. F., Ruiz, C., 2013. Complementarity Modeling in Energy Markets. International Series in Operations Research \& Management Science. Vol. 180. SpringerVerlag, New York.

Green, R., Vasilakos, N., 2011. The long-term impact of wind power on electricity prices and generating capacity. University of Birmingham economics discussion paper. https://www . birmingham.ac.uk/Documents/college-social-sciences/business/economics/2010-papers/ economics-papers-2011/economics-papers-2011/11-09.pdf.

Hirth, L., 2013. The market value of variable renewables: The effect of solar wind power variability on their relative price. Energy Economics 38, 218-236.

Hledik, R., Greenstein, G., 2016. The distributional impacts of residential demand charges. The Electricity Journal 29 (6), 33-41.

Hobbs, B. F., Helman, U., 2004. Complementarity-based equilibrium modeling for electric power markets. In: Bunn, D. W. (Ed.), Modelling Prices in Competitive Electricity Markets. Wiley, New York, Ch. 3.

Höschle, H., Le Cadre, H., Smeers, Y., Papavasiliou, A., Belmans, R., 2018. An ADMM-based Method for Computing Risk-Averse Equilibrium in Capacity Markets. IEEE Transactions on Power Systems 33 (5), 4819-4830.

IRENA, 2017a. Electricity storage and renewables: Costs and markets to 2030. http://www . irena.org/-/ media/Files/IRENA/Agency/Publication/2017/Oct/IRENA_Electricity_Storage_Costs_2017.pdf.

IRENA, 2017b. IRENA Cost and Competitive Indicators. Rooftop Solar PV. http://www.irena.org/-/ media/Files/IRENA/Agency/Publication/2017/Dec/IRENA_Cost_Indicators_PV_2017.pdf.

Laws, N. D., Epps, B. P., Peterson, S. O., Laser, M. S., Wanjiru, G. K., 2017. On the utility death spiral and the impact of utility rate structures on the adoption of residential solar photovoltaics and energy storage. Applied Energy 185, 627-641.

MIT Energy Initiative, 2016. Utility of the future. https://www.vreg.be/sites/default/files/ 
20180111_studie_vreg_statusrapport_v11___eindrapport.pdf.

Picciariello, A., Reneses, J., Frias, P., Söder, L., 2015. Distributed generation and distribution pricing: why do we need new tariff design methodologies? Electric Power Systems Research 119, 370-376.

Pollitt, M. G., 2018. Electricity Network Charging in the Presence of Distributed Energy Resources: Principles, Problems and Solutions. Economics of Energy \& Environmental Policy 7 (1), 89-104.

Poncelet, K., Höschle, H., Delarue, E., Virag, A., D’haeseleer, W., 2017. Selecting Representative Days for Capturing the Implications of Integrating Intermittent Renewables in Generation Expansion Planning Problems. IEEE Transactions on Power Systems 32 (3), 1936-1948.

Reneses, J., Ortega, M. P. R., 2014. Distribution pricing: theoretical principles and practical approaches. IET Generation, Transmission \& Distribution 8 (10), 1645-1655.

Saguan, M., Meeus, L., 2014. Impact of the regulatory framework for transmission investments on the cost of renewable energy in the EU. Energy Economics 43, 185-194.

Schittekatte, T., Meeus, L., 2018. Least-cost distribution network tariff design in theory and practice. EUI working paper RSCAS 2018/19.

Schittekatte, T., Momber, I., Meeus, L., 2018. Future-proof tariff design : Recovering sunk grid costs in a world where consumers are pushing back. Energy Economics 70, 484-498.

Simshauser, P., 2016. Distribution network prices and solar PV : Resolving rate instability and wealth transfers through demand tariffs. Energy Economics 54, 108-122.

Synergrid, 2018. Synthetic Load Profiles (SLP). http://www.synergrid.be/index.cfm?PageID=16896\& language_code=NED, (accessed: 17/07/2018).

Usaola, J., Morena, M., Saenz de Miera, G., Rivier, J., Bueno, M., 2009. Effect of Wind Energy on Capacity Payment. The Case of Spain. http://www.aaee.at/2009-IAEE/uploads/presentations_iaee09/Pr_ 24_Usaola_Garcia_Julio.pdf, 10th IAEE European Conference, Vienna.

Uzawa, H., 1960. Walras' tatonnement in the theory of exchange. The Review of Economic Studies 27 (3), 182-194.

VREG, 2017. Marktmonitor. https://www.vreg.be/sites/default/files/document/rapp-2017-14. pdf.

Zhao, J., Hobbs, B. F., Pang, J.-S., 2010. Long-Run Equilibrium Modeling of Emissions Allowance Allocation Systems in Electric Power Markets. Operations Research 58 (3), 529-548. 


\section{Appendix A. Motivation ADMM}

Consider the equilibrium problem (A.1)-(A.2), consisting of the optimization problems of all agents $a \in \mathcal{A}(\mathrm{A} .1)$ and and one shared constraint (A.2):

$$
\begin{aligned}
& \forall a \in \mathcal{A}: \quad \operatorname{Max}_{x_{a} \in \mathcal{X}_{a}} f\left(x_{a}\right)+\lambda \cdot x_{a}, \\
& \sum_{a \in \mathcal{A}} x_{a}=C, \quad(\lambda)
\end{aligned}
$$

The optimization problems of consumers (2)-(16), conventional generators (17)-(19), renewable generators (20)-(22) and interconnector agent (23)-(25) can all be generally formulated as (A.1), while Equation (A.2) is a general formulation of the market clearing constraint (26). Höschle et al. (2018) reformulate (A.1)-(A.2) as an optimal exchange optimization problem (A.3), with $\boldsymbol{x}=\left(x_{a}\right)_{a \in \mathcal{A}}$ :

$$
\operatorname{Max}_{\boldsymbol{x} \in \mathcal{X}} \quad \sum_{a \in \mathcal{A}} f\left(x_{a}\right) \text { s.t. } \quad \sum_{a \in \mathcal{A}} x_{a}=C \quad(\lambda),
$$

Höschle et al. (2018) show that the KKT-conditions of (A.3) correspond to the KKTconditions of (A.1)-(A.2), implying that the solution of optimization problem (A.3) is an equilibrium of the problem (A.1)-(A.2). As (A.3) is a classical optimal exchange problem, ADMM is a well-suited technique to find the optimum (Boyd et al., 2011), and by extension to find an equilibrium of (A.1)-(A.2).

We show now that an equilibrium problem with a cost recovery coupling constraint (27), which has a different structure than the market clearing constraint (26), can be reformulated similarly. Consider equilibrium problem (A.4)-(A.5), which has a shared constraint (A.5) similar to the cost recovery constraint (27):

$$
\begin{aligned}
& \forall a \in \mathcal{A}: \quad \operatorname{Max}_{x_{a} \in \mathcal{X}_{a}} \quad f\left(x_{a}\right)-\operatorname{tar} \cdot x_{a}, \\
& \operatorname{tar} \cdot \sum_{a \in \mathcal{A}} x_{a}=C, \quad(\phi)
\end{aligned}
$$

We rewrite coupling constraint (A.5) as follows:

$$
\sum_{a \in \mathcal{A}} x_{a}=\frac{C}{\operatorname{tar}}, \quad(\mu)
$$


The KKT conditions of equilibrium problem (A.4)-(A.6) are (A.6)-(A.7).

$$
\nabla_{x_{a}} f\left(x_{a}\right)-\operatorname{tar}=0, \quad \forall a \in \mathcal{A}
$$

We now formulate optimization problem (A.8), with associated KKT conditions (A.6) and (A.9).

$$
\begin{aligned}
& \operatorname{Max}_{\boldsymbol{x} \in \mathcal{X}} \sum_{a \in \mathcal{A}} f\left(x_{a}\right) \quad \text { s.t. } \quad \sum_{a \in \mathcal{A}} x_{a}=\frac{C}{\operatorname{tar}}(\mu), \\
& \nabla_{x_{a}} f\left(x_{a}\right)-\mu=0, \quad \forall a \in \mathcal{A}
\end{aligned}
$$

The KKT conditions of optimization problem (A.8) are thus equivalent to those of the equilibrium problem (A.4)-(A.6), if the dual variable of the shared constraint in the optimum, $\mu^{*}$, equals the tariff in equilibrium, tar* Because optimization problem (A.8) is an optimal exchange problem, we can solve it using ADMM. During the iterative solution procedure, we enforce the aforementioned necessary condition for equivalence. In each iteration of the ADMM algorithm, $\mu$ is updated according to the imbalance of the coupling constraint:

$$
\mu^{n+1}=\mu^{n}-\rho \cdot\left(\sum_{a \in \mathcal{A}} x_{a}-\frac{C}{t a r}\right)
$$

To ensure that $\mu^{*}=t a r^{*}$, we adapt the update rule as follows:

$$
\mu^{n+1}=\mu^{n}-\rho \cdot\left(\sum_{a \in \mathcal{A}} x_{a}-\frac{C}{\mu^{n}}\right)
$$

Once the ADMM algorithm converges to the optimal solution of the optimization problem (A.6), then $\sum_{a \in \mathcal{A}} x_{a}=\frac{C}{\mu^{*}}$, implying that $\mu^{*}$ fulfills the cost recovery constraint (A.6), thus implying that $\mu^{*}=\operatorname{tar}^{*}$. As a result, the outcome of the adapted ADMM algorithm is also a Nash equilibrium solution of the equilibrium problem (A.4)-(A.6). 


\section{Appendix B. Implementation ADMM}

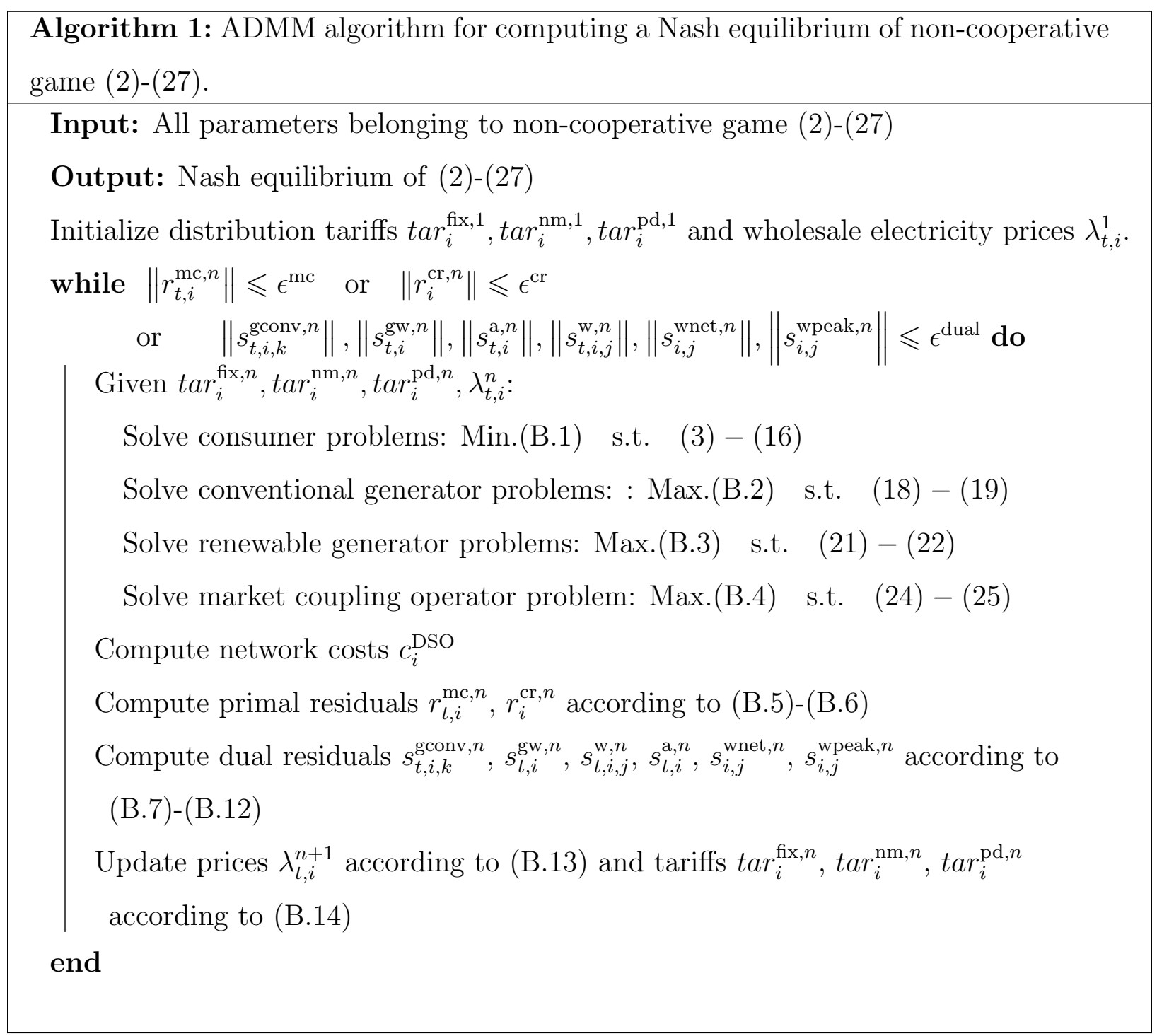

Pseudo-code describing the ADMM algorithm, inspired by Höschle et al. (2018), is provided above. First, the wholesale electricity prices and distribution tariffs are initialized. In each iteration $n$, the optimization problems of consumers, conventional generators, renewable generators and the market coupling operator are solved considering fixed wholesale market prices and distribution tariffs. Quadratic penalty terms, that become zero when the equilibrium is reached, are added to the objectives of the optimization problems in order to facilitate convergence (Appendix B.1). Afterwards, the network costs $c_{i}^{\mathrm{DSO}}$ are updated according to Eq. (28) in the sunk cost case or Eq. (29) in the variable cost case. Based 
on the decisions of the agents and the updated network costs, the primal residuals, i.e., the imbalances of the coupling constraints, $r_{t, i}^{\mathrm{mc}, n}$ and $r_{i}^{\mathrm{cr}, n}$ are calculated (Appendix B.2). The dual residuals, which measure the rate of change of the variables, are also calculated (Appendix B.2). The prices and tariffs are then updated based on the primal residuals (Appendix B.3). The algorithm is terminated when the norms of both the primal and dual residuals fall below a threshold $\left(\epsilon^{\mathrm{mc}}, \epsilon^{\mathrm{cr}}\right.$ and $\left.\epsilon^{\text {dual }}\right)$. An adequate choice of the factors $\rho$, present in the penalty terms of the objectives ((B.1)-(B.4)) and the price and tariff updates ((B.13)-(B.14)), is essential for obtaining convergence in reasonable time.

\section{Appendix B.1. Adapted objectives}

In the ADMM algorithm, the objectives of the residential consumers (2), conventional generators (17), renewable generators (20) and market coupling operator (23) are replaced by Equations (B.1)-(B.4). Compared to the original objectives, quadratic penalty terms have been added to steer the agents towards correcting possible market imbalances and avoid overreactions to small price updates. In the consumer objective (B.1), there is one penalty term for the electricity market balance (third line), one for the cost recovery balance under a net-metering tariff (fourth line) and one for the cost recovery balance under a peak demand-based tariff (fifth line). ${ }^{22}$ We obtain good convergence by choosing $\rho=100$ for the electricity market balance penalty and $\rho=0$ for the cost recovery balance penalty terms. For the other agents, there is only one penalty term, each time for the electricity market balance. For these agents, we choose a penalty term of $\rho=10$. The imbalances in the penalty terms are scaled with $\frac{1}{\mathrm{~N}_{\mathrm{P}}}$ and/or $\frac{1}{\mathrm{~N}_{\mathrm{C}}}$ respectively. $\mathrm{N}_{\mathrm{P}}$ denotes the amount of participants in each wholesale market, equalling six in our case, counting three conventional generators, one renewable generator, one (aggregated) consumer and one market coupling operator. $\mathrm{N}_{\mathrm{C}}$ denotes the amount of consumers per country, equalling 4.8 million in the base case. The adapted optimization problems are no longer linear, but quadratic convex. These type of problems can still be solved with commercial solvers such as Gurobi. When the algorithm

\footnotetext{
${ }^{22}$ There is no penalty term for the fixed tariff case as that is a trivial case in which the consumers do not impact cost recovery.
} 
converges, the imbalances will converge towards zero, implying that the penalty terms also converge to zero.

$$
\begin{aligned}
\text { Min. } & \sum_{t \in \mathcal{T}} \lambda_{t, i}^{n} \cdot w_{t, i, j}^{n}+\mathrm{IC}^{\mathrm{pv}} \cdot \operatorname{cap}_{i, j}^{\mathrm{pv}, n}+\mathrm{IC}^{\mathrm{s}} \cdot \operatorname{cap}_{i, j}^{\mathrm{s}, n}+\mathrm{u}_{i}^{\mathrm{fix}} \cdot \operatorname{tar}_{i}^{\mathrm{fix}, n} \\
+ & \mathrm{u}_{i}^{\mathrm{nm}} \cdot \operatorname{tar}_{i}^{\mathrm{nm}, n} \cdot w_{i, j}^{\mathrm{net}, n}+\mathrm{u}_{i}^{\mathrm{pd}} \cdot \operatorname{tar}_{i}^{\mathrm{pd}, n} \cdot w_{i, j}^{\mathrm{peak}, n} \\
+ & \sum_{t \in \mathcal{T}} \rho\left(w_{t, i, j}^{n}-\left(w_{t, i, j}^{n-1}+\frac{1}{\mathrm{~N}_{\mathrm{C}} \cdot \mathrm{N}_{\mathrm{P}}}\left(\sum_{k \in \mathcal{K}} g_{t, i, k}^{\mathrm{conv}, n-1}+g_{t, i}^{\mathrm{w}, n-1}+a_{t, i}^{n-1}-\mathrm{D}_{t, i}^{\mathrm{nres}}-\sum_{j \in \mathcal{J}} \mathrm{N}_{i, j} \cdot w_{t, i, j}^{n-1}\right)\right)\right)^{2} \\
+ & \mathrm{u}_{i}^{\mathrm{nm}} \cdot \rho\left(w_{i, j}^{\mathrm{net}, n}-\left(w_{i, j}^{\mathrm{net}, n-1}+\frac{1}{\mathrm{~N}_{\mathrm{C}}}\left(\frac{c_{i}^{\mathrm{DSO}}}{\operatorname{tar}_{i}^{\mathrm{nm}, n-1}}-\sum_{j \in \mathcal{J}} \mathrm{N}_{i, j} \cdot w_{i, j}^{\mathrm{net}, n-1}\right)\right)\right)^{2} \\
& +\mathrm{u}_{i}^{\mathrm{pd}} \cdot \rho\left(w_{i, j}^{\mathrm{peak}, n}-\left(w_{i, j}^{\mathrm{peak}, n-1}+\frac{1}{\mathrm{~N}_{\mathrm{C}}}\left(\frac{c_{i}^{\mathrm{DSO}}}{\operatorname{tar}_{i}^{\mathrm{pd}, n-1}}-\sum_{j \in \mathcal{J}} \mathrm{N}_{i, j} \cdot w_{i, j}^{\text {peak }, n-1}\right)\right)\right)^{2}
\end{aligned}
$$

$\operatorname{Max} . \quad \sum_{t \in \mathcal{T}}\left(\lambda_{t, i}^{n}-\mathrm{VC}_{k}\right) \cdot g_{t, i, k}^{\text {conv }, n}-\mathrm{IC}_{k}^{\text {conv }} \cdot \operatorname{cap}_{i, k}^{\text {conv }, n}$

$$
-\sum_{t \in \mathcal{T}} \rho\left(g_{t, i, k}^{\mathrm{conv}, n}-\left(g_{t, i, k}^{\mathrm{conv}, n-1}-\frac{1}{\mathrm{~N}_{\mathrm{P}}}\left(\sum_{k \in \mathcal{K}} g_{t, i, k}^{\mathrm{conv}, n-1}+g_{t, i}^{\mathrm{w}, n-1}+a_{t, i}^{n-1}-\mathrm{D}_{t, i}^{\mathrm{nres}}-\sum_{j \in \mathcal{J}} \mathrm{N}_{i, j} \cdot w_{t, i, j}^{n-1}\right)\right)\right)^{2}
$$

$\operatorname{Max} . \quad \sum_{t \in \mathcal{T}} \lambda_{t, i}^{n} \cdot g_{t, i}^{\mathrm{w}, n}-\mathrm{IC}^{\mathrm{w}} \cdot \operatorname{cap}_{i}^{\mathrm{w}, n}$

$$
-\sum_{t \in \mathcal{T}} \rho\left(g_{t, i}^{\mathrm{w}, n}-\left(g_{t, i}^{\mathrm{w}, n-1}-\frac{1}{\mathrm{~N}_{\mathrm{P}}}\left(\sum_{k \in \mathcal{K}} g_{t, i, k}^{\mathrm{conv}, n-1}+g_{t, i}^{\mathrm{w}, n-1}+a_{t, i}^{n-1}-\mathrm{D}_{t, i}^{\mathrm{nres}}-\sum_{j \in \mathcal{J}} \mathrm{N}_{i, j} \cdot w_{t, i, j}^{n-1}\right)\right)\right)^{2}
$$

$\operatorname{Max} . \quad \sum_{t \in \mathcal{T}}\left(\sum_{i \in \mathcal{I}}\left(\lambda_{t, i}^{n} \cdot a_{t, i}^{n}\right)-\mathrm{CT} \cdot f_{t}^{n}\right)$

$$
-\sum_{t \in \mathcal{T}} \sum_{i \in \mathcal{I}} \rho\left(a_{t, i}^{n}-\left(a_{t, i}^{n-1}-\frac{1}{\mathrm{~N}_{\mathrm{P}}}\left(\sum_{k \in \mathcal{K}} g_{t, i, k}^{\mathrm{conv}, n-1}+g_{t, i}^{\mathrm{w}, n-1}+a_{t, i}^{n-1}-\mathrm{D}_{t, i}^{\mathrm{nres}}-\sum_{j \in \mathcal{J}} \mathrm{N}_{i, j} \cdot w_{t, i, j}^{n-1}\right)\right)\right)^{2}
$$

\section{Appendix B.2. Residuals}

The primal residuals of the market clearing and cost recovery constraints are defined by Equations (B.5)-(B.6) respectively. The network costs $c_{i}^{\mathrm{DSO}}$ are updated in each iteration, following Eq. (28) or (29), before calculating $r_{i}^{\mathrm{cr}, n}$. The primal residuals correspond to the imbalances of the coupling constraints. Equations (B.7)-(B.12) define the dual residuals of the decision variables of the agents. They are measures for the rate of change of these 
variables between iterations. Note that they also indicate the level of the penalty terms in the objectives. The dual residuals are defined for all decision variables that appear in the coupling constraints. The parameter $\rho$ in each equation takes the value of the corresponding penalty term in the objectives (B.1)-(B.4).

$$
\begin{aligned}
& r_{t, i}^{\mathrm{mc}, n}=\sum_{k \in \mathcal{K}} g_{t, i, k}^{\mathrm{conv}, n}+g_{t, i}^{\mathrm{w}, n}+a_{t, i}^{n}-\mathrm{D}_{t, i}^{\mathrm{nres}, n}-\sum_{j \in \mathcal{J}} \mathrm{N}_{i, j} \cdot w_{t, i, j}^{n}, \quad \forall t \in \mathcal{T}, i \in \mathcal{I} \\
& r_{i}^{\mathrm{cr}, n}=\sum_{j \in \mathcal{J}} \mathrm{N}_{i, j}\left(\mathrm{u}_{i}^{\mathrm{fix}}+\mathrm{u}_{i}^{\mathrm{nm}} \cdot w_{i, j}^{\mathrm{net}, n}+\mathrm{u}_{i}^{\mathrm{pd}} \cdot w_{i, j}^{\mathrm{peak}, n}\right)-\frac{c_{i}^{\mathrm{DSO}}}{\mathrm{u}_{i}^{\mathrm{fix}} \cdot \operatorname{tar}_{i}^{\mathrm{fix}, n}+\mathrm{u}_{i}^{\mathrm{nm}} \cdot \operatorname{tar}_{i}^{\mathrm{nm}, n}+\mathrm{u}_{i}^{\mathrm{pd}} \cdot \operatorname{tar}_{i}^{\mathrm{pd}, n}},
\end{aligned}
$$

$s_{t, i, k}^{\text {gconv }, n}=\rho\left(\left(g_{t, i, k}^{\text {conv }, n}-x_{t, i}^{\mathrm{mc}, n}\right)-\left(g_{t, i, k}^{\text {conv }, n-1}-x_{t, i}^{\mathrm{mc}, n-1}\right)\right), \quad \forall t \in \mathcal{T}, i \in \mathcal{I}, k \in \mathcal{K}$

with $\quad x_{t, i}^{\mathrm{mc}, n}=\frac{1}{\mathrm{~N}_{\mathrm{P}}}\left(\sum_{k \in \mathcal{K}} g_{t, i, k}^{\text {conv }, n}+g_{t, i}^{\mathrm{w}, n}+a_{t, i}^{n}-\sum_{j \in \mathcal{J}} \mathrm{N}_{i, j} \cdot w_{t, i, j}^{n}\right)$

$s_{t, i}^{\mathrm{gw}, n}=\rho\left(\left(g_{t, i}^{\mathrm{w}, n}-x_{t, i}^{\mathrm{mc}, n}\right)-\left(g_{t, i}^{\mathrm{w}, n-1}-x_{t, i}^{\mathrm{mc}, n-1}\right)\right), \quad \forall t \in \mathcal{T}, i \in \mathcal{I}$

$s_{t, i, j}^{\mathrm{w}, n}=\rho\left(\left(w_{t, i, j}^{n}-\frac{1}{\mathrm{~N}_{\mathrm{C}} \cdot \mathrm{N}_{\mathrm{P}}} \cdot x_{t, i}^{\mathrm{mc}, n}\right)-\left(w_{t, i, j}^{n-1}-\frac{1}{\mathrm{~N}_{\mathrm{C}} \cdot \mathrm{N}_{\mathrm{P}}} \cdot x_{t, i}^{\mathrm{mc}, n-1}\right)\right), \quad \forall t \in \mathcal{T}, i \in \mathcal{I}, j \in \mathcal{J}$

$s_{t, i}^{\mathrm{a}, n}=\rho\left(\left(a_{t, i}^{n}-x_{t, i}^{\mathrm{mc}, n}\right)-\left(a_{t, i}^{n-1}-x_{t, i}^{\mathrm{mc}, n-1}\right)\right), \quad \forall t \in \mathcal{T}, i \in \mathcal{I}$

$s_{i, j}^{\text {wnet }, n}=\rho\left(\left(w_{i, j}^{\text {net }, n}-\frac{1}{\mathrm{~N}_{\mathrm{C}}} \cdot x_{i}^{\mathrm{cr}, n}\right)-\left(w_{i, j}^{\mathrm{net}, n-1}-\frac{1}{\mathrm{~N}_{\mathrm{C}}} \cdot x_{i}^{\mathrm{cr}, n-1}\right)\right), \quad \forall i \in \mathcal{I}, j \in \mathcal{J}$

with $\quad x_{i}^{\mathrm{cr}, n}=\sum_{j \in \mathcal{J}} \mathrm{N}_{i, j}\left(\mathrm{u}_{i}^{\mathrm{nm}} \cdot w_{i, j}^{\mathrm{net}, n}+\mathrm{u}_{i}^{\mathrm{pd}} \cdot w_{i, j}^{\mathrm{peak}, n}\right)$

$s_{i, j}^{\text {wpeak }, n}=\rho\left(\left(w_{i, j}^{\text {peak }, n}-\frac{1}{\mathrm{~N}_{\mathrm{C}}} \cdot x_{i}^{\mathrm{cr}, n}\right)-\left(w_{i, j}^{\text {peak }, n-1}-\frac{1}{\mathrm{~N}_{\mathrm{C}}} \cdot x_{i}^{\mathrm{cr}, n-1}\right)\right), \quad \forall i \in \mathcal{I}, j \in \mathcal{J}$

\section{Appendix B.3. Price and tariff updates}

The wholesale electricity prices are updated according to the primal residuals of the market clearing, scaled with a factor $\rho$ (Eq. (B.13)). Similarly, the distribution tariffs are updated according to the primal residuals of the cost recovery constraint, scaled with a factor $\rho$ (Eq. (B.14)). For the wholesale electricity price updates, the choice of $\rho=0.1$ leads to good convergence. For the tariff update, the choice depends on the tariff structure. For a fixed or peak demand tariff we set $\rho=\frac{10}{\mathrm{~N}_{\mathrm{C}}}$; for a net-metering tariff we set $\rho=\frac{10^{-5}}{\mathrm{~N}_{\mathrm{C}}}$. 


$$
\begin{aligned}
& \lambda_{t, i}^{n+1}=\lambda_{t, i}^{n}+\rho \cdot r_{t, i}^{\mathrm{mc}, n}, \quad \forall t \in \mathcal{T}, i \in \mathcal{I} \\
& u_{i}^{\mathrm{fix}} \cdot \operatorname{tar}_{i}^{\mathrm{fix}, n+1}+u_{i}^{\mathrm{nm}} \cdot \operatorname{tar}_{i}^{\mathrm{nm}, n+1}+u_{i}^{\mathrm{pd}} \cdot \operatorname{tar}_{i}^{\mathrm{pd}, n+1}= \\
& u_{i}^{\mathrm{fix}} \cdot \operatorname{tar}_{i}^{\mathrm{fix}, n}+u_{i}^{\mathrm{nm}} \cdot \operatorname{tar}_{i}^{\mathrm{nm}, n}+u_{i}^{\mathrm{pd}} \cdot \operatorname{tar}_{i}^{\mathrm{pd}, n}+\rho \cdot r_{i}^{\mathrm{cr}, n}, \quad \forall i \in \mathcal{I}
\end{aligned}
$$

\section{Appendix B.4. Convergence example}

We illustrate the convergence of the ADMM algorithm for a scenario with a peak demand tariff in the reference country and a net-metering tariff in the neighboring country, assuming sunk costs, in Figure B.8. The wholesale electricity prices are initialized at zero; the distribution tariffs are initialized so that the network costs would be recovered if all consumers were passive. For the primal residual of the market clearing we set a stopping criterion of $\epsilon^{\mathrm{mc}}=10$, implying that the root of the sum of squares of all imbalances in the studied 288 timesteps (12 days of 24 hours) should be less than 10 MW. For the primal residual of the cost recovery constraint, we set a stopping criterion of $\epsilon^{\mathrm{rc}}=100$, implying that the root of the sum of squares of the unrecovered costs in both countries, divided by their respective tariffs is smaller than 100. Finally for the dual residuals, we set a stopping criterion of $\epsilon^{\text {dual }}=10$. Note that the dual residuals are also a measure for the level of the penalty terms in the objectives. The parameters $\rho$ are set as described in the previous sections. Under these settings, the algorithm converges after 1257 iterations.

Figure B.8a indicates that the primal residuals, especially $r_{i}^{\mathrm{cr}, n}$, reach the stopping criterion before all dual residuals do. The primal residual of the cost recovery constraint decreases further to well below the required level. Figure B.8b shows that the dual residual of the conventional generation is the last one to fulfill the stopping criterion. The dual residuals of the consumers' offtake and wind generation decrease far below the required level. In Figure B.8c we see that the average wholesale price in both countries slowly converges to the same level of $49.8 € / M W h$ in both countries. Finally, Figure B.8d presents the evolution of the distribution tariffs in both countries, showing that they converge quicker than the wholesale prices. These figures clearly show that satisfying the market clearing balance, governed by 
the wholesale electricity prices $\lambda_{t, i}$ takes longer than satisfying the cost recovery constraint, governed by the distribution tariffs $\operatorname{tar}_{i}^{\mathrm{fix}}, \operatorname{tar}_{i}^{\mathrm{nm}}, \operatorname{tar}_{i}^{\mathrm{pd}}$.

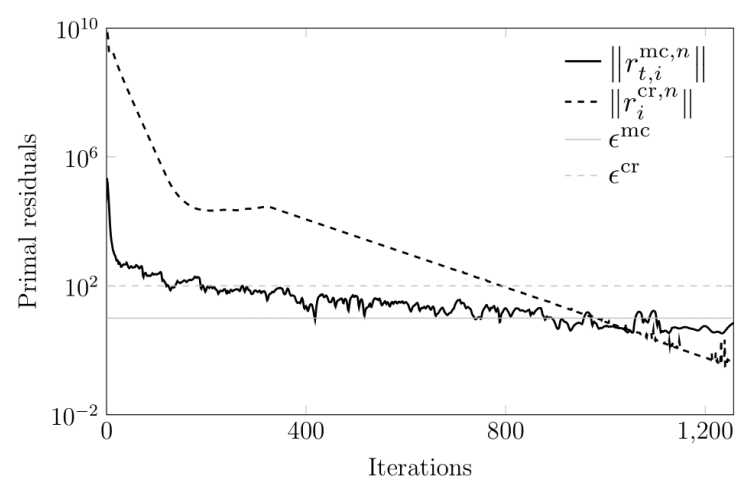

(a) Primal residuals.

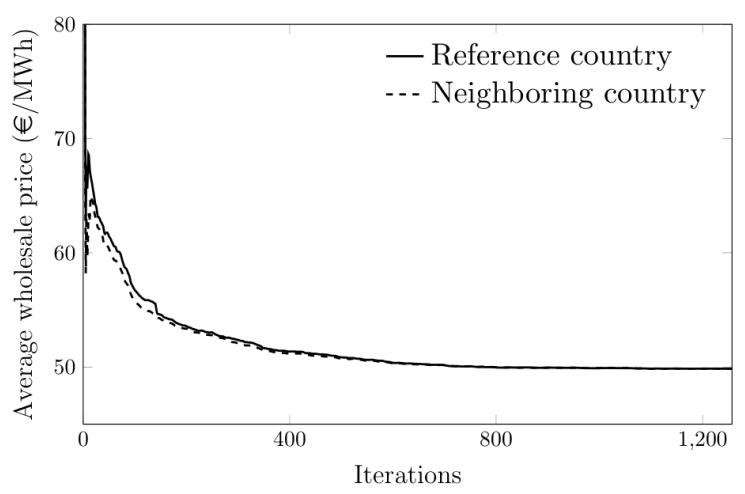

(c) Average wholesale electricity prices.

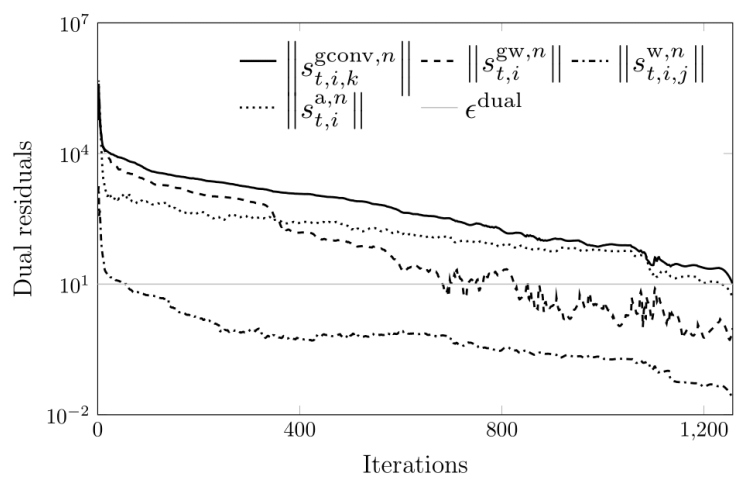

(b) Dual residuals.

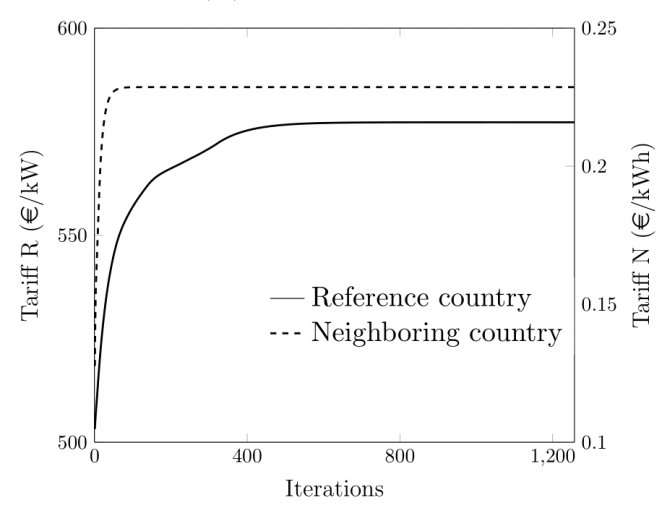

(d) Distribution grid tariffs.

Figure B.8: Convergence of ADMM algorithm.

\section{Appendix B.5. Multiple equilibria}

For each scenario, we determine one equilibrium as described in the previous section, i.e., the wholesale electricity prices are initialized at zero and the distribution tariffs are initialized so that the network costs would be recovered if all consumers were passive. As discussed in Section 3.3, multiple equilibria exist because there are multiple ways of operating storage systems in order to obtain the same final energy costs. In order to find a different equilibrium, we thus aim to modify the charging and discharging patterns of the storage systems. To this end, we run the same algorithm, initializing the prices and tariffs to their respective values 
in the first equilibrium, for an adapted version of the model. More specifically, Equations (B.15) and (B.16) are added to the optimization problems of the consumers (2)-(16):

$$
\begin{aligned}
& c h_{t, i, j} \leqslant \mathrm{RM}_{t, i, j} \cdot M, \quad \forall t \in \mathcal{T}, i \in \mathcal{I}, j \in \mathcal{J} \\
& d c_{t, i, j} \leqslant \mathrm{RM}_{t, i, j} \cdot M, \quad \forall t \in \mathcal{T}, i \in \mathcal{I}, j \in \mathcal{J}
\end{aligned}
$$

RM1 and RM2 are two arrays, randomly filled with zeros and ones, while M is a large number. As such, Equations (B.15) and (B.16) impose that the storage system cannot be charged/discharged during certain hours, while they impose no limits in the other hours. The outcome of this model typically differs from the outcome of the original model, especially in storage operation. The obtained result, however, is not necessarily an equilibrium of the original equilibrium problem (2)-(27). The algorithm is thus executed again, in its original form, i.e., without Equations (B.15) and (B.16), initialized according to the outcome of the modified problem, i.e., including Equations (B.15) and (B.16). The result obtained from this last run of the algorithm is an equilibrium of the original problem (2)-(27), but it may differ from the originally obtained equilibrium. This process is repeated until we retrieve the desired number of equilibria. 